\title{
BLACK WEALTH MOBILITY
}

by

Tasha Sinclair Riley, Bachelors of Social work, University of Windsor, 2018

\author{
An MRP \\ presented to Ryerson University \\ in partial fulfillment of the \\ requirements for the degree of \\ Master of Social work \\ in the Program of \\ Social work
}

Toronto, Ontario, Canada, 2019

(C) Tasha Sinclair Riley 2019 


\section{AUTHOR'S DECLARATION FOR ELECTRONIC SUBMISSION OF A MRP}

I hereby declare that I am the sole author of this MRP. This is a true copy of the MRP, including any required final revisions.

I authorize Ryerson University to lend this MRP to other institutions or individuals for the purpose of scholarly research

I further authorize Ryerson University to reproduce this MRP by photocopying or by other means, in total or in part, at the request of other institutions or individuals for the purpose of scholarly research.

I understand that my MRP may be made electronically available to the public. 


\author{
ABSTRACT \\ Black Wealth Mobility \\ Master of Social work, 2019 \\ Tasha Sinclair Riley \\ Program of Social work, \\ Ryerson University
}

This is a narrative storytelling qualitative research study on Black wealth mobility. Through a Critical Race Theory and Anti-Black Racism lens, this study allows the experiences of Black social service workers to help understand the route and tools used when navigating wealth mobility, and creating a separate space to define the Black experience throughout this process. Existing research shows there are significant gaps in attaining wealth for Black communities, and very little surrounding solutions for these gaps. As social service providers, participants were able to not only make suggestions for social supports to be developed, but also to utilize counter-storying telling to pinpoint issues existing within the current social sector which also contribute to these gaps in Black communities. This research not only gave a space for Black bodies to express and share their experiences, but also a space to critically reflect on the work done in these communities. 


\section{ACKNOWLEDGEMENTS}

I would like to take this opportunity to thank all the bodies that have contributed to my

professional and educational development. Beginning with my MRP supervisor Samantha Wehbi who has been patient in her guidance and through the development of creating this paper. Every single one of my participants who took the time to include and discuss their rich personal experiences with wealth mobility. Also, I would like to thank Susan Preston whom I have worked with closely for the duration of my time at Ryerson, aiding in guiding my professional and educational transitions and experiences. 


\section{DEDICATION}

This paper is dedicated to both my parents Vanessa Riley and Raymond Riley. Who have shown continuous emotional and financial support throughout my entire existence, through my schooling and to this very point in time. They have been the motivation of this paper, and my first-hand primary examples of Black wealth mobility. The lessons I have learned from them will continue through generations of my bloodline and run through veins of my community. 


\section{TABLE OF CONTENTS}

CHAPTER 1. INTRODUCTION \& THEORETICAL FRAMEWORK .................................... 1

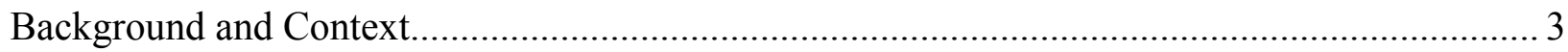

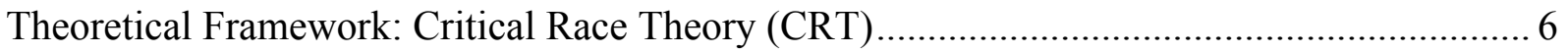

Theoretical Framework: Anti-Black Racism (ABR) ............................................................ 8

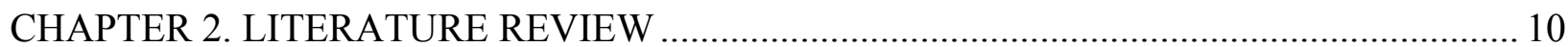

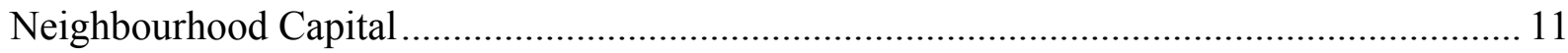

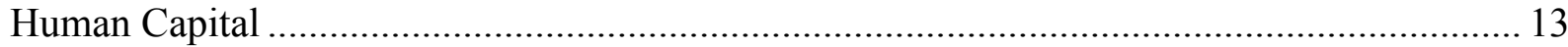

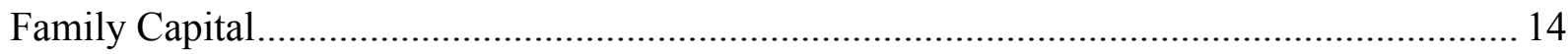

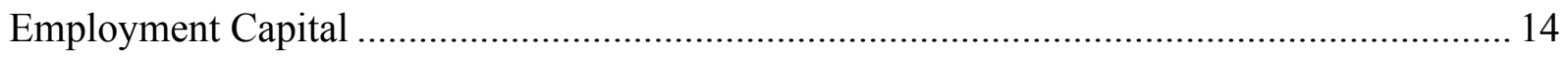

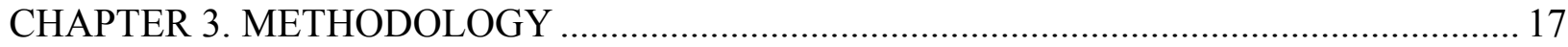

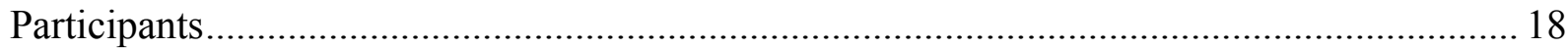

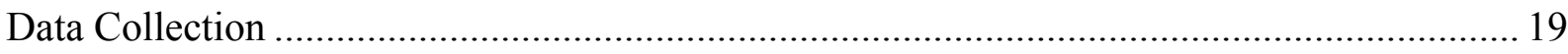

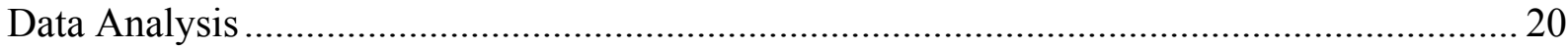

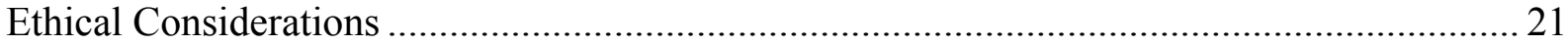

CHAPTER 4. FINDINGS \& DISCUSSION ............................................................. 23

Identifying, Defining \& Understanding 'Black Wealth Mobility' ....................................... 24

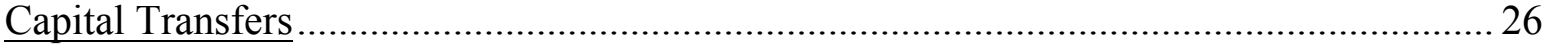

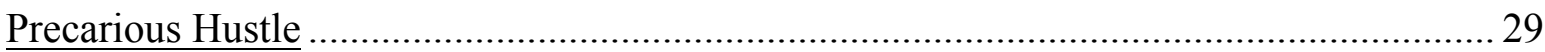

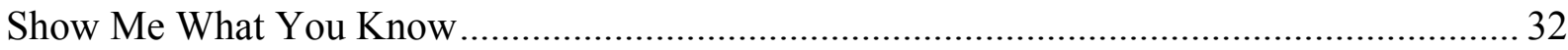

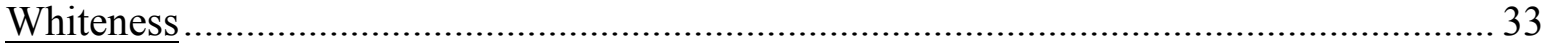

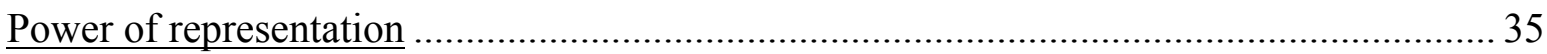

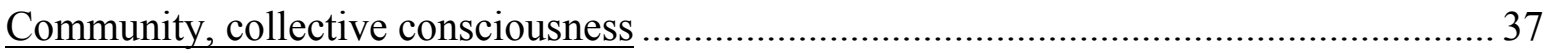

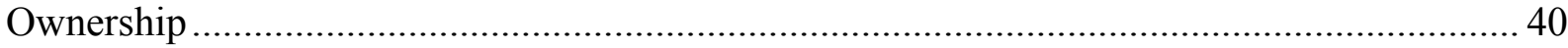

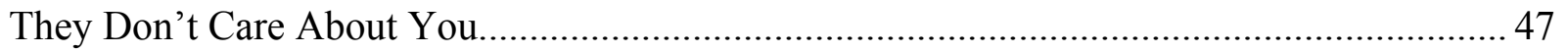

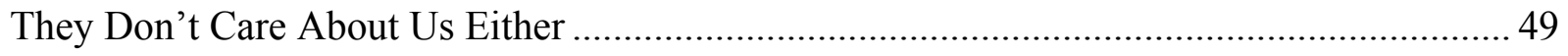

CHAPTER 5: MOVING FORWARD--IMPLICATIONS \& CONCLUSION ........................... 52

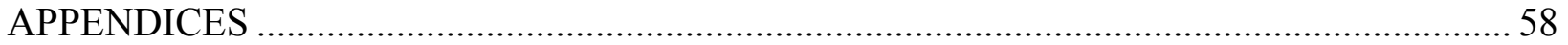

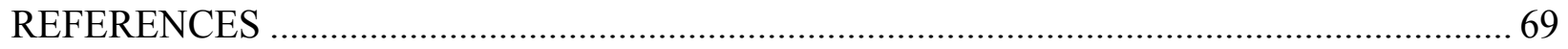




\section{LIST OF APPENDICES}

$\begin{array}{lr}\text { Appendix A - Recruitment Email } & \text { Page } 58\end{array}$

$\begin{array}{lr}\text { Appendix B - Consent Form } & \text { Page } 60\end{array}$

$\begin{array}{ll}\text { Appendix C - Interview Guide } & \text { Page } 65\end{array}$

$\begin{array}{ll}\text { Appendix D - Ethics Approval certificate } & \text { Page } 68\end{array}$ 


\section{CHAPTER 1. INTRODUCTION \& THEORETICAL FRAMEWORK}

The notion of Black Wealth Mobility challenges dominant narratives that rely on cultural and individual 'deficiencies' as primary causes for the differences between race and wealth mobility, while also developing social work informed programs and policies to combat antiBlack racism within social institutions. As Canada's reputation continues to be upheld by narratives of 'inclusivity' and 'multiculturalism,' a critical reflection is required that challenges how these narratives are experienced through individuals' lived realities. When juxtaposing Canadian narratives with Canadian lived experiences, racial disparities, inequalities and economic oppressions tend to dominate. Despite Canada's economic growth and the increasing diversity of its population; the lived experiences of those existing within these contexts are colour-coded (Block \& Grace-Edward, 2011, p.3).

Consider how Black bodies and their communities are understood through a narrative that deems its population as being financially and economically immobile. These "systems of representation function as subtle cultural mechanisms of oppression and social control that shape cultural norms and personal beliefs, while concealing the process [which] produce[s] them" (Hasford, 2016, p.158). Dominant narratives of Black wealth immobility have contributed to the ongoing harm faced by our communities, instead of bringing awareness to broader systemic issues. And so, personally growing up and observing an overwhelming amount of Black bodies experiencing poverty, it was not only normalized but also understood as deserving and resulting from their innate 'Blackness' and incompetence. Arguably, this belief was a byproduct of a society that attributes cultural differences of being of African descent to account for the social phenomena of racial wealth gap (Herring \& Henderson,2016, p.5). This is an element within the Black Canadian experience; and I also had accepted this narrative as legitimate. The historical 
persistence of this dominant narrative has functioned to solidify the Black body's social positioning and for this positioning to be naturalized. This is the narrative that this study seeks to challenge.

For this MRP study, wealth mobility is defined as the individual ability to accumulate, grow and increase assets to ensure one's financial stability, including that of family members. This concept will also extend to account for generational wealth and the ability to transfer accumulated wealth and assets within a lifetime. Mainstream research's practice of studying racialized poverty in attempts to identify racial inequalities has resulted in major gaps within knowledge production — specifically within the Canadian context, — by neglecting to provide frameworks that counter the dominant narratives surrounding this phenomena. As Connell (2007) discussed "it is not enough to name the metropole; the job of social science is to analyze it..." (p.16), to ultimately aid in dismantling the dominant discourses they discuss. And so, concepts of Black wealth mobility and economic sustainability become fictional constructs when limited knowledge is produced to support its existence; presenting Black bodies as inferior beings deserving of the oppression imposed upon them.

Connell (2007) introduces an alternate approach "in contrast to the familiar practice [of] middle-class academics study[ing] down on the poor, the marginal and the troubled" (p.216). By refocusing mainstream research and utilizing counter storytelling within my study, I will be able to capture the racialized experiences of those who professionally navigate major social institutions. Social institutions that not only shape the experiences of attaining wealth mobility, but could potentially operate as the barriers that prevent certain bodies from having access. In an effort to capture counter-narratives, the process of 'studying up' will create a space for "telling the stories of those people whose experiences are not often told...[and] also a tool for exposing, 
analyzing, and challenging the majoritarian stories of racial privilege" (Solórzano \& Yosso, 2002, p.32). The purpose of this approach is to "understand the social processes- the institutions, interests and strategies - that generate catastrophes" (Connell, 2007, p.216). The development of this knowledge will operate as a form of resistance in challenging dominant narratives of Black wealth (im)mobility while also posing potential solutions to these findings.

\section{Background and Context}

The whitewashing of the Black community's history has deliberately disregarded the communities which existed and exhibited wealth mobility in recent history, for example: the Black Wallstreet in Tulsa, Oklahoma or Africville in Nova Scotia. These were Black communities that were subject to segregation, resulting in a Black economic market space separated from Whites. This is not addressed in support of segregation — but, rather to highlight the importance of these communities as they are prime examples which attest to the existence of Black wealth mobility before environmental racism infiltrated their communities. Yet, they are often overshadowed by dominant narratives of poverty and economic deficiency. With access to government resources to account for the maintenance of a community (i.e. garbage disposal, running water, etc.), Messer (2011) highlights the impact and function of segregation as a colonizing power; "segregation (and economic detour) gave to the Black professional a virtually protected market, but that represented a mixed blessing...they profited economically, by avoiding intense competition from their white counterparts...”. (p.7). Segregation was a tool used in an attempt to limit the wealth mobility of Black bodies by limiting their access to human, family, employment, social and neighbourhood capitals. Ironically, Tulsa, Oklahoma actually experienced thriving economic achievement during this period of segregation (Messer, 2011, p.7), but was destroyed by surrounding White communities during political tensions. Similarly, 
Africville was once deemed to be a promising community by Black leaders in Nova Scotia which later became subject to environmental racism from the Halifax government. Nelson (2008) discusses how "racism and neglect eventually made its people vulnerable to the urban renewal process and [government-instructed] relocation" of approximately 400 residents (p.920).

Being able to pinpoint Black communities whose sole existence challenges dominant narratives allows us to understand the process of what took place thereafter, the destruction of these communities, and their connection to poverty rates within Black communities today. Although Black Wallstreet and Africville existed in separate locations, their transition through similar experiences of wealth mobility to economic neglect alludes to the existence of a social oppression that limits the wealth mobility of Black bodies. This becomes visible when considering "blacks have made significant economic, labour, and educational strides, from the histotiograhical point of emancipation...[yet] almost no tangible economic foundation" (Bowman, 2016, p.94) to account for this progress. This experience is strongly tied to the North American history of exploiting Black bodies for their labour in the economic development of the land, without these bodies having access to the profits of their work. In challenging dominant narratives, Bowman (2016) concludes that this is the result of the correlation between "black middle class families [seeing] considerable progress in some areas that influence wealth and asset growth [yet still,] these outcomes demonstrate weak correlations to calculable wealth and asset attainment" (p.93). This line of thinking redirects the conversation from questioning why Black communities lack wealth mobility, to investigating societal oppressions which create and enforce wealth immobility in Black communities.

To provide context for the prevalence of this issue within Canadian boarders, reports have repeatedly described the existence of racialized poverty in Toronto, as "the colour of money 
[being] mainly white" (Contenta, 2018). It is quite alarming when considering Toronto is home to 43 percent of all racialized bodies within Canada (Social Development Canada, 2013, "Geographically concentrated," para.1) and accounts for 41 percent of all racialized persons living in poverty (Social Development Canada, 2013, "Concentrated in three provinces" para. 1). This ongoing trend raises red flags of a 'societal oppression,' yet limited attention is being attributed to developing solutions for these issues. When narrowing the scope, Statistics Canada (2013) reported Black bodies account for 15 percent of the racialized population within Toronto ("Much Diversity," para. 1), yet 19 percent of the population is living in poverty ("Table 10: Visible minority groups, 2006 percent distributions of persons living in poverty," table 1). According to Hulchanski, the 2016 census shows that Black bodies now account for nine percent of the population with thirteen percent living in poverty. The correlation between these two-time periods present the immobility of wealth within the community, and its ability to persist regardless what portion of the population they account for. This would then lead to drawing conclusions of wealth mobility within Black communities being tied and restricted to structural issues within society.

Coming from the perspective of a middle-class Black woman, first generation Jamaican Canadian - my positioning provides a unique perspective. I acknowledge the privilege I hold in this position; my English carries no significant accent, I am rooted and familiar with the Canadian culture, I am located in an economically stable community, I am post-secondary educated, cis-gendered, heterosexual and able-bodied. With this in mind, I am also a Black woman in a White man's world - developing a combination of privilege and oppression intertwined within my personal positioning. Similar to other Black bodies whose positionality may differ, I can attest to the social organization of Black bodies and how our points of access 
differ from those of our White counterparts and/or other racialized bodies. All which have resulted from the Anti-Blackness that runs rampant in Canadian culture, creating significant economic implications for Black bodies. Meaning, that regardless of my pillars of 'privilege' I also experience the benchmarks of oppression that come with being Black, and a Black woman at that. Although the "Black racial identity is critical to understanding the potential for social [and wealth] mobility" (Charles et al., 2015, p.281) I will make a continuous effort not to homogenize our population and its varied experiences. I have found that most research and data collection fail to acknowledge or "pay scant attention to how nativity, social class, and/or mixed raced origins may differentially impact" individual experiences (Charles et al., 2015, p.281), which can result in erasing some bodies from the narrative. This is important for the reader to note because differing benchmarks of oppression can alter the experience of 'Blackness' depending on the varying access to privilege and oppression that their identities embody. This MRP will attempt to encompass the layered experience of Black bodies navigating themselves to wealth mobility and economic sustainability, and in order to do so, relies on a theoretical framework that is guided by Critical Race Theory and Anti-Black Racism.

\section{Theoretical Framework: Critical Race Theory (CRT)}

Critical Race Theory (CRT) calls for the need for "new 'theorizing methods' to conduct research that would answer the problems posed" (Solórzano \& Yosso, 2002, p.24). My MRP follows this same narrative as the purpose of this research goes beyond developing conclusions which outline the prevalence of racial disparities in wealth mobility; but, to also propose solutions to these problems through the lived experiences of those directly impacted. Coming from a: 
broad literature base in law, sociology, history, ethnic studies, and women's

studies...[CRT] advances a strategy to foreground and accounts for the role of race and racism...and works toward the elimination of racism as part of a larger goal of opposing or eliminating other forms of subordination. (Solórzano \& Yosso, 2002, p.25)

One of the founders of CRT, Derrick Bell, expressed the need for a space of non-white academia in the early 1980 's, to present critical thoughts on oppression, its operation in society, and within their own experiences (Subotnik, 1998, p. 684):

The time has come for white liberal authors who write in the field of civil rights to redirect their efforts and to encourage their colleagues to do so as well .... There are many other important subjects that could, and should, engage their formidable talents. As these scholars stand aside, nature will take its course [through] talented and innovative minority writers and commentators. The dominant scholars should affirmatively encourage their minority colleagues to move in this direction, as well as to make the change possible.

The structure of this study will follow a similar suit in several ways. On one hand, my identity as a Black woman permits me to take up this space in research and to also include CRT as the theoretical framework. On the other hand, the participant requirements and the recruitment process are also influenced by concepts within CRT; where Black professionals who navigate social institutions and are social service providers will be centred for their experiences and expertise to be documented. Academic discussions of CRT also call for the need to define the three elements of racism including (Solórzano \& Yosso, 2002, p. 24): “(a) One group deems itself superior to all others (b) the group that is superior has the power to carry out the racist behaviour, and (c) racism benefits the superior group while negatively affecting other racial and/or ethnic groups." As the researcher, I will be keeping these elements in mind and seeking 
them out through the analysis of participant's storytelling. As my Masters MRP's main objective is to challenge dominant narratives of Black wealth mobility, individual experiences will be used to recreate the picture of Black communities, and contribute to the process of rebuilding the economic prosperity of Black communities that once was.

\section{Theoretical Framework: Anti-Black Racism (ABR)}

Combined with the CRT framework, I will also use Anti-Black Racism (ABR) to guide this research paper and structure the approach and analysis of study findings. Coined by Dr. Akua Benjamin, the tenets of ABR "highlight the unique nature of systemic racism on BlackCanadians and [our] history, as well as experiences of slavery and colonization of people of Black-African descent in Canada" (Anti-Black Racism, 2018, para.2). It is important to note that the term 'Black' will be used in this MRP to acknowledge the shared experiences of oppression of those who are of African descent, identify as Black and are living within the Canadian context. The term Black will not be used to homogenize these experiences, but to acknowledge a functioning oppression that targets a group of visible minorities within the population.

$\mathrm{ABR}$ is an arena structured specifically to investigate "policies and practices rooted in Canadian institutions such as, education, health care, and justice that mirror and reinforce beliefs, attitudes, prejudice, stereotyping and/or discrimination towards people of Black-African descent" (Anti-Black Racism, 2018, para.1).

One key act of resistance highlighted in ABR is enabling "support from all levels of government, institutions, businesses, schools, healthcare, social service and community agencies and individuals" (Anti-Black Racism, 2018, para.3). This element of ABR will be extracted and implemented into this study in order to draw conclusions in study findings, and in designing the proposal of policies and programs that should be developed. This will create space to challenge 
dominant narratives surrounding the Canadian persona. It will allow the realities of antiBlackness to resurface in painting a more accurate picture of the Canadian experience that is inclusive of all bodies that must endure it. By acknowledging its existence and that it runs rampant within Canadian structures, we also then develop the capacity to "resist and overcome this anti-black reality, [as] it must first be recognized and admitted" (Tecle, 2016, p.24).

A review of the literature will be discussed next to look at previous studies surrounding the subject of Black wealth mobility. There will be critiques and main themes critical to this study outlined, and discussed in depth to structure the readers understanding. Following, will be a discussion of the study's methodology, where narrative storytelling and counter-storytelling will be outlined and described. The methodology chapter also provides details about participants, the methods of data collection, data analysis, ethical considerations; and my positionality as the researcher. 


\section{CHAPTER 2. LITERATURE REVIEW}

Wealth immobility is one of the dominant narratives surrounding Black bodies, where they are continuously positioned in spaces with restricted access to resources, and are then labelled as 'ghetto' and 'low-income.' Wealth mobility is a matrix of multiple moving parts that are interdependent of one another. By understanding the matrix and the points of access that provide white bodies with generations of wealth mobility, we can then construct means by which Black bodies can do the same — but, through actions of resistance defined within their lived experiences. Identification of these key variables, their patterns and how they are differentially impacted dependent on one's individual race, "highlights the need for targeted policies that reinforce and expand opportunities for all families to build wealth over the life course" (Meschede et al, 2016, p. 77). The study conducted by Meschede et al. (2016) highlighted "larger family transfers [(family capital)], consistent long-term homeownership [and] resources available within a community $[($ neighbourhood capital $)]$, ...white-collar occupations [(employment capital)]" (p. 77), human capital, and social capital as the primary factors which influence wealth mobility. This will serve as the groundwork of this study; and these main themes will be discussed in this chapter.

\section{Social Capital}

Bowmen (2016) also discusses social capital in his study as the "participation in associations and general trust in others'" (p.94); not what you know, but who you know. The main elements of social capital presented were: “(a) obligations and expectations for reciprocal exchange between individuals, (b) normative elements of social control, and (c) the presence and value of information channels" (Bowmen, 2016, p.94). Highlighting trust, bonding and bridging are integral components in the relationship established between individuals and the workforce. 
The workforce representing the interpersonal relations between colleagues, as well as the relationship one establishes with workforce as an institution. The role relationship building has in accessing wealth mobility becomes problematic when the workforce as an institution is designed to keep Black bodies out or in bottom tier of the workplace hierarchy. Hasford (2016) identifies the "theoretical games" (p.163) that Black bodies play within the workplace in attempts to navigate around dominant narratives that challenge their competence, limit their opportunities and purposely restrict their potential. The concept of theoretical games "is not intended to downplay or trivialize the severity of workplace racism, but rather to highlight the strategic, skillful, and cooperative dynamics of navigating and resisting racism and dominant cultural narratives" (p.163) within the workplace setting.

Hasford (2016) identifies narratives such as "The Scary Black Person" (p.164) or "The Underachiever" (p.164) which result in the Black body constantly negotiating and defending their position in an institution from being subject to exclusion and condescension (p.164). As a result, Hasford (2016) found that many Black bodies experience performance anxiety at three varying levels; “(a) race awareness (b) racism sensitivity; and (c) anger and sadness” (p.168). Through social capital, it then becomes extremely difficult for Black bodies to build purposeful relationships with colleagues - who are also upholding racism in the workplace. It also becomes extremely difficult for Black bodies to develop positive relationships with the workplace as an institution because of the anti-Black culture that it perpetuates.

\section{Neighbourhood Capital}

Neighbourhood capital is a reoccurring theme in the scholarship and holds dual meaning in the context of wealth mobility. On one hand, the impact of the environment on one's wealth mobility is determined by: (a) its ability to provide access to resources within home 
communities; on the other hand, (b) it looks at how the environment and social location impact homeownership as being a positive indicator of one's expected upward movement in wealth quintiles. Beginning with the discussion of an individual's home community and their access to resources, Meschde et al. (2016) found that; "neighbourhood poverty differs greatly between white and Black families" (p.81). Within Graham's et al., (2015) study, one participant captures the experience of neighbourhood capital in Toronto having an adverse effect on wealth mobility: “most of the people in my neighbourhood don't work. Like, the guys don't work... No one's hiring me. And, you can't make money, you can't give anything to your family” (p.779).

The dual role of neighbourhood capital intersects at varying degrees. Race determines "which neighbourhoods [are] stable and which neighbourhoods had housing values that were either volatile or declining over time" (Meschde et al. 2016, p.84) impacting the quality and value of a neighbourhood. Meschde et al., (2016) found that "building wealth tends to be more likely in predominantly white neighbourhoods, while predominantly black or latino neighbourhoods more often see greater home value volatility or declines" (p.84). Considering that "choice also partly explains the makeup of low-income neighbourhoods. Some members of ethnic groups prefer to live where their communities are most numerous, giving them easy access to the shops and cultural or religious services that facilitate integration or simply make life more enjoyable" (Contenta, 2018, para.10) which increases their visibility, making them easy targets for depleting resources and restricting access within their communities. Although Meshde's et al., (2016) study was situated within the United States, similar trends can be found on Canadian soil. Hulchanski draws conclusions that show 68 percent of low-income neighbourhoods are housed by racialized bodies, and 31 percent by White bodies — although whites account for 49 percent of Toronto's population (Contenta, 2018). In contrast, within high- 
income neighbourhoods, 73 percent of residents are white, while only 3 percent are Black (Contenta, 2018). This calls for the reshaping of dominant narratives that surround Black communities living poverty: communities which are predominantly Black are not given access to the same elements of wealth mobility that their white counterparts are. And so, their communities continue to lack resources, financial security and opportunity, thus initiating downward trends of wealth mobility.

\section{Human Capital}

Bowman (2016) defines human capital as the "skills that an individual acquires through education, training, and other means that improve productivity and market earnings...[including those] inherent and developed" (p.93). Human capital has four main elements which impact one's ability to develop high levels of capital; "(a) innate ability, (b) schooling, (c) school quality and non-schooling investments and (d) training" (p.94). Differential access to these elements produce varying outcomes which either limit or support individuals in accessing wealth mobility.

Although, Black bodies have taken educational strides in developing their human capital, their progress is not reflected through generations of wealth and asset attainment (Bowman, 2016, p.94). And so, this guides us to look at how "a combination of historical factors and contemporary discrimination has maintained disproportionate outcomes and opportunities" (Bowman, 2016, p.94) for Black bodies. This would mean considering the impact low neighbourhood/environment capital has in accessing quality resources of human capital development. It also calls for research to look at the ways Black bodies navigate their wealth mobility through alternative modes of accessing opportunities, aside from the traditional method of seeking out institutions to provide trainings and knowledge. This would highlight the selfresiliency of Black bodies and navigating systems which were designed to keep them out. 


\section{Family Capital}

Family capital plays a unique role that feeds into a broader concept of generational wealth. This is especially important when considering that (Mesche et al., 2016) "the wealth of a child's parents while the child is in the family is a predictor of how well the child does as an adult" (p.78). There are several factors which influence family capital's relation to wealth mobility, such as family structure, private family transfers and inheritance, occupation, income, employment, and entrepreneurship (Meschde et al., p.79). Because the operation of this capital is largely dependent on the ability of family to transfer capitals and resources, the lack thereof creates a ripple effect of weak transfers within families. In comparison, within Meschde's et al., (2016) study they found "at the lower end of the relative wealth distribution, $49 \%$ of black families are stuck in the lowest wealth quintile, as compared to $38 \%$ of white families" (p.82). And so, considering the social and economic status that Black bodies are forced into, they do not benefit to the same extent or in the same ways white families may from inheritances and transfers (Meschde et al., 2016, p.87). The protective element of family transfers is then weakened in comparison to their white counterparts, and reduces the likelihood of Black families to experience trauma that does not result in downward relative wealth mobility (Meschde et al., 2016, p.88). These gaps call for the development of policies and programs that target these racialized differences and aid Black families in building generational wealth.

\section{Employment Capital}

Another implicating factor of wealth mobility is employment capital which refers to the internal policy structure of workplace environments - also, impacted by external government policies around employment. In essence, this is the difference between having access to a minimum wage, part-time positions and being able to secure a full-time job with benefits. 
Graham et al (2015), also discuss how "black families are concentrated in jobs with little employment capital, undermining their prospects for building wealth" (p.83). The three main components affecting employment capital are outlined by Graham et al., (2015) as; (a) a comprehensive set of wealth building benefits, (b) flexible schedule and (c) consistent work (p.83). Elements such as human and social capital also play a role in accessing and qualifying for positions which carry high employment capital. Occupations that carry high employment capital tend to also be those which are overrepresented by white workers often providing benefit packages to support employees (and their families) from negative life events (i.e. insurance, health care, severance pay etc.) (Meschde et al., 2016, p.86).

Considering the racism Black bodies experience within the workforce, this limits their access to social capital, and in turn, effects their access to positions that contain high employment capital. It is important to note that much of the racism experienced is concealed, and often times becomes enmeshed within the everyday small, routine practices of day-to-day interactions - not necessarily preformed as intentional acts of racial bigotry (Branker, 2017, p.208). Thus, Black bodies experience a glass door effect in obtaining employment beyond precarious work as "aspirations towards labour market attachment are determined in part by how that social capital becomes manifested in the employee-employer interaction" (Graham et al., 2016, p.777). Yet still, even when Black bodies do secure a position that carries high employment capital there is a glass ceiling still in effect that prevents upward movement within the workplace. On one hand, Branker's (2017) participants felt as though their race was a large part in their inability to be promoted; "Management, particularly higher management were all of one gender and one nationality. They might give you a little supervisory role which is lower level management, but you will not go any further than that" (p.209). It gets really interesting 
when looking at the cases in which Black bodies did receive access to higher levels of management, and participants discuss the experience of race-based abuse from white junior staff. This was largely due to the resentment they felt because they — as white Canadians — had to report to a minority, Black (potentially immigrant and/or woman) person (p.210). This situation presents a never-ending cycle of Black bodies fighting for capital that they should have equal access to, but are continuously being undervalued due to the makeup of their identities.

Within the realm of employment capital, there was also a common theme of resistance performed by Black bodies. Bradford (2014) poses "the decline in barriers to Black entrepreneurship from the effects of discrimination in the labor and capital markets" have worked in Black bodies' favour for the upward movement of wealth mobility. With this being said, entrepreneurship is very much a privileged form of resistance. When understanding how the capitals are interconnected, elements such as low neighbourhood/environment capitals, low family capital and restricted access to financial resources can make it difficult for the Black body to support the venture of entrepreneurship. Nonetheless, Bradford (2014) found within his study that entrepreneurship provides an alternative lane for Black bodies to "enter and successfully compete in mainstream business markets" (p.256) while also securing forms of capital through non-traditional methods. Bradford (2017) attributes the decline in barriers for Black entrepreneurs as they are no longer subject to the effects of discrimination within the traditional white collar workforce (p.256). Within entrepreneurship there also exists an increased level of employment capital as it offers entrepreneurs greater freedom to control their workplace dynamic, interactions and environment (Bradford, 2017, p.256). 


\section{CHAPTER 3. METHODOLOGY}

Narrative storytelling was used within this research study to grasp the lived experiences of Black social service providers' personal journey with wealth mobility, and the experiences of working alongside Black clients who were possibly also navigating through wealth mobility. The use of this approach will centre the experiences of participants, and utilize their storytelling as a primary source of knowledge for informing policy and programs. Narratives serve as a way of characterizing and identifying phenomena within the human experience (Connelly \& Clandinin, 1990, p.2); where stories are able to illustrate both the collective and individual experiences of issues surrounding race (Bell, 2009, p. 108). As a methodology, narrative storytelling "helps bring us closer to issues that are usually seen as out there and separate from us, or that we are afraid to see as part of our lives, such as racism" (Bell, 2009, p.109). This methodology is also a powerful tool that can that invites and provides space for everyone at the table by validating everyones experiences. It is then used as a tool for creating knowledge that concerns the complexities of social society, which we all share collectively but experience differently depending on where we are positioned within it (Bell, 2009, p.109).

Counter-storytelling specifically will be used to challenge dominant narratives that surround Black bodies and wealth mobility. Counter-storytelling can be defined as a "method of telling stories of those people whose experiences are often not told" (Solorzabo \& Yosso, 2002 p.32). The purpose of this method is to shift the perspective of wealth mobility within Black communities and amongst Black bodies from being a personal issue to one that requires collective social recognition. It can be used as (Solorzabo \& Yosso, 2002) "tool for exposing, analyzing, and challenging majoritarian stories of racial privilege" (p.32), and in bringing the voices of those who are directly impacted to the forefront. As CRT targets methodologies that 
critically challenge biological and cultural deficit narratives (Solorzabo \& Yosso, 2002, p.37) counter-storytelling becomes the outlet from which this can happen authentically, and from those whose experiences are directly impacted by the social phenomena being studied. The type of counter-storytelling that will be used is 'other people's stories or narratives,' where Black participant's stories will be used to reveal the experiences of navigating and observing racism (Solorzabo \& Yosso, 2002, p.37), thus providing opportunities for challenging the current social order.

\section{Participants}

As mainstream research often maintains focus on the most marginalized and oppressed populations to make sense of social phenomena's, this study will redirect this common approach by using the methodological tool of 'studying up' as Connell (2007) would describe. Connell (2007) defines studying up as:

In contrast to the familiar practice where middle-class academics study down on the poor, the marginal and the troubled. Power structure research set out to study the rich instead, and duly produced important findings on the concentration of wealth and the shape of corporate elites. (Connell, 2007, p.216)

In understanding the matrix of wealth mobility this can be carried out in one of two ways; (a) the focus could be on how white bodies access and maintain wealth mobility; or, (b) studying how Black bodies who have navigated social institutions have accessed wealth mobility. Although option (a) will give direct insight to the power structure of wealth mobility, studying white bodies to make sense of Black bodies experiences creates major gaps in the research and rejects the purpose of narrative counter-storytelling within the CRT framework: centring the voices of those who are often left at the margins. And so, all participants within this study were 
individuals who: (a) are Black, and identify as having African decent (b) worked at least one year within the field of social work/services and (c) are located within the Greater Toronto Area (GTA). Each criterion serves a unique purpose to the focus of this study; criteria (a) presents an opportunity to understand racialized experience without needing to access the most vulnerable within the population. Criteria (b) will influence the kind of stories which emerge within the study, as participants will have extensive knowledge of the internal structure and organization of social institutions due to their educational background, and their workplace experiences. Their workplace experiences also present opportunities for developing knowledges of resistance, which are informed through their educational and professional backgrounds. This will present a multi-layered context where participants will be able to speak — to an extent - on both the personal experiences and how they may utilize tools of resistance to navigate the experiences of their Black clients. Finally, criteria (c) is largely based on the feasibility of this study, and also to narrow in on the experiences of Black bodies within a specific geographical location.

Recruitment occurred through email. Much of the participants were former colleagues or individuals I had met prior within the field of social service work. Please see Appendix A for the recruitment email attachment initially sent to all participants. After the first few participants had agreed, snowball sampling was used to acquire the last participant who was also sent the recruitment email. Participants were then sent a copy of the consent form to review and promised that it would be provided to sign the day of during the study. Please see Appendix B for a copy of the consent form.

\section{Data Collection}

This study was conducted in a focus group format with three Black social service providers. With the consent of all participants, the focus group was audio recorded and then the 
recording was stored securely during the process of analysis. Participants were asked open ended questions that guided the conversation about their experiences with attaining wealth mobility. They were also asked to speak on the experiences they have when working alongside Black clients who are either facing financial restrictions, or also navigating towards wealth mobility. For example, some of the questions asked included: "Have you ever acted in resistance to aid clients in accessing financial supports?" or "Can you identify specific policies or program structures that presented a barrier or aided in financial mobility?" Please see Appendix C for the interview guide.

\section{Data Analysis}

The audio recordings were first transcribed verbatim, to then conduct a thematic analysis of the data collected. Braun and Clarke (2006) argue that the use of thematic analysis is essential to the research process and should be treated as a foundational method in qualitative analysis (p.78). The flexibility of thematic analysis provides the researcher with a "method for identifying, analyzing and reporting themes within the data" (p.79). This process has allowed for me as the researcher to acknowledge forms of resistance that have supported Black bodies with wealth mobility, while also finding common issues within policy and programs that present barriers to Black bodies attempting to access wealth mobility. After transcribing the data, I first immersed myself in it to become familiar with the depth and breadth of its content by rereading, taking notes, and marking ideas for coding to return to later (Braun \& Clarke, 2006, p.87). Next, I generated a list of ideas about what the data could inform the research study on, and what made these aspects interesting (Braun \& Clarke, 2006, p.88). This is where I began developing the thematic map that conceptualized the patterns within the data and the relationships between every theme found (Braun \& Clarke, 2006, p.87). 
Next, I went through the process of refining and narrowing in on main themes that informed my research study question, by evaluating its validity based on what was said through participants' narrative stories (Braun \& Clarke, 2006, p.91). Once this was complete I was then able to get into more detail about the essence of each individual theme, and determining which aspect of the data it captures and contributes to study findings (Braun \& Clarke, 2006, p.92). Much of this process is guided and rooted in "a 'giving voice' approach 'involv[ing] carving out unacknowledged pieces of narrative evidence that we select, edit, and deploy to border our arguments" (Braun \& Clarke, 2006, p.80).

\section{Ethical Considerations}

The sensitivity of the research topic Black wealth mobility poses a potential threat especially when considering the harm previous research has done in contributing to dominant narratives about Black bodies and their communities. These elements have been taken into consideration and mitigated through the research study design by centering participants' voices

with an explicit attempt to challenge dominant narratives. Also, being a Black woman in the field of social work, conducting a study about my community alongside former colleagues and/or those who may share similar experiences, has provided participants with a 'safe space' within the research. Another mitigation tactic I have instilled within the research design is to send all participants a copy of the final report before submission, allowing them to review and confirm or deny portions of the findings as their contribution to the final report.

Additional ethical considerations within this study include the relationship I shared with some participant(s) prior to the research study, and them potentially feeling obligated to partake in this study in order to avoid conflict within our pre-established relationship(s). To avoid those contacted in the recruitment process feeling obligated, all participants were told their 
participation is not required, nor will it affect any personal relationship we may have or had prior to this request. Also, because financial experiences are more private portions of an individual's life, there was a potential of psychological risk in feeling discomfort throughout the duration of the focus group. Due to the sensitive nature of the discussion, participants had the freedom to decline participation or withdrawal from the study without any implication throughout the entire process of the research. They were also able to make this choice up until May 1, 2019, where all data collected from them would be immediately destroyed and not included in the report if they chose to be excluded from the research after the focus group.

Participation within this study also posed a potential risk of social stigma for those individuals and their places of employment if sensitive data was not kept confidential or individuals are identifiable within study findings. However, all steps were taken to ensure participants' confidentiality throughout the research process to minimize these risks. When reporting study findings, the region in which participants live was not reported; and pseudonyms were used to identify participants separately and to lessen the reader's ability to identify them. 


\section{CHAPTER 4. FINDINGS \& DISCUSSION}

The discussion of wealth mobility would be incomplete without allowing for a space to examine the economic positioning of individuals within racialized communities, specifically within the Canadian context. The stories narrated within this chapter all derive from personal experiences with the intention of documenting, and passing on knowledge for future generations to add to, learn from, and possibly challenge. Within the discussion of wealth mobility, this research allows for a space to be carved out specifically for Black bodies. It allows for expanding the general understanding of wealth mobility to encompass the various elements intertwined in the Black experience. Themes from the various stories shared have been constructed from interview data, including my personal experiences and responses as the researcher to identify my influence in this research. Findings are organized thematically, drawing on several stories that were found to be consistent amongst participants.

The themes synthesized are supported by participants' stories based on commonalities found throughout their varying experiences. As this research aims to contribute and create knowledge surrounding the Black experience; how participants tell their stories, the context of, and the language used, will all be included verbatim to aid the reader in understanding the stories exactly how the participants intended for them to be shared. Readers can expect a mixture of social work terminology and Greater Toronto Area (GTA)-based slang as participants illustrate their experiences and connect them to broader societal constructs. The authenticity that these two realms of language bring to the research humanize the participants within the social service provider role, while also allowing for their cultural roots as Black Canadians to still be present and relatable to those outside of the realm of social work. In avoiding the white-washing of their stories and sustaining a consistent, universal interpretation of content presented; phrases and 
words that are culturally specific to GTA's slang will be discussed and defined by both participants and me in my role as the researcher.

Moreover, in remaining authentic to the stories and experiences of the participants, fellow social work professionals who engage in this text could potentially devalue the credibility of their stories as they may challenge core social work values and foundational elements of this field. Nonetheless these stories are important for exposing the realities of social work from the perspective of Black bodies engaging within the profession - a perspective often not called upon, or discussed as whiteness continues to dominate social work and its understanding of social services. To modify the stories so they are consistent with mainstream social work, undercuts the purpose of Black narrative story-telling and counter story-telling, both chosen to serve as primary tools of this research to specifically challenge dominant narratives that the social work profession upholds, and expose the reality of the good Samaritan persona that social work relies on to conduct violence within its practice. As this research will discuss the personal experiences of Black professionals - unless participants clearly identify otherwise — in no way I as the researcher am determining who has and who has not achieved Black wealth mobility. This research will highlight the barriers, tools of resistance and unique elements central to the Black experience of navigating themselves to wealth mobility. These narratives will depict the reality of Black professionals who navigate wealth mobility, while also serving as an access point and support system for service users - often times, service users who are also navigating their own wealth mobility.

\section{Identifying, Defining \& Understanding 'Black Wealth Mobility'}

The introduction of the focus group began by first presenting the concept of Black wealth mobility to the participants by putting forth my personal understanding of what it meant to me 
when entering the research. Much of this concept was influenced by personal experiences watching my family manage their wealth mobility, and also information from the literature review. The themes of family capital, environment/neighbourhood capital, social capital, employment capital and human capital all remained consistent throughout participants' responses in narrowing in on this concept. Much of the concepts discussed were also intertwined with identified tools of acquiring and building Black wealth mobility. The discussion began with:

Researcher: uhm I would like to start off by defining wealth mobility. I personally have identified it as; wealth mobility being the individual ability to accumulate, grow and increase assets to ensure one's financial stability, uhm, including that of their family. And this concept can also extend to generational wealth and the ability for wealth to be transferred and accumulated uhm over a life time.

Cassidy: yeah

Reese: For the most part, I didn't have one coming in so this is like a good starting point. As participants agreed to the posed understanding of wealth mobility, they continued to expand their interpretation of the concept to include their personal experiences navigating as a Black body; an experience that they found to differ from those surrounding them, including their white counterparts and other racialized bodies.

Researcher: mhhmkay, so I kinda want to pull on, uhm, some of the things you were saying 'as Black people.' So like, have you noticed — or uh, — this is a question posed to all three of you, have you noticed your identity as a Black individual, like, affect the kind of barriers that were maybe put in place?

Cassidy (15:59): one hundred percent 
The identification of this unique experience requires that the process of analysis has the capacity to expand and create a separate space where 'Black wealth mobility' specifically attends to the racialized differences in navigating wealth mobility itself. This frames the concept of wealth mobility to serve as the baseline, groundwork for understanding societal structures and institutions that control the circulation of wealth. In many ways participants' stories aligned with the set capitals discussed prior, but I found these capitals took different forms and held varying meanings from the traditional understanding. When accounting for racialized bodies who navigate wealth mobility, there were many pillars that were unique to the Black experience.

Critical Race Theory (CRT) specifically targets this discrepancy in experiences amongst Black bodies, and acknowledges that; "despite advances in reducing overt racism and discrimination, covert and institutional racism continues to operate through policies and practices embedded within social structures, systems, and institutions that systematically reflect and produce racial inequality" (Kolivoski, K. M., Weaver et al., 2014, p.270). This inequality can be reflected in the call for this research to have a distinction between wealth mobility and Black wealth mobility, as this research is seeking to account for the unique experiences of inequality imposed upon onto Black bodies. There are two main features which emerged in defining Black wealth mobility consistent throughout the research; (1) the ability to transfer capital that holds monetary value (physical and informational) throughout and within generations, and (2) employment capital/consistent income (precarious hustle).

\section{$\underline{\text { Capital Transfers }}$}

The key feature of capital transfers is the process of transferring (inheritance and/or knowledge) through generations. It is essential to the concept of building Black wealth 'mobility, ' and intersects with many of the elements that contribute to this experience. The 
element of transferring intentionally expands the idea of simply just the acquisition of wealth within Black communities; to that of a generational wealth, and sustaining the fluidity of its mobility. As one of the participants Cassidy notes, the information his parents passed down of past experiences was an essential guide through his own personal journey:

Cassidy: Now when it comes to me, and now they're trying to do things differently, they have to start from the bottom right. So, they're telling me stuff that they wish they knew, and then some stuff they're still figuring out. They're now coming into their fifties, and they're like yeah, we're just figuring this out now. So, Cassidy here, do this. Versus many of my white colleagues came out the womb!

Researcher, Cassidy \& Reese: laughter

Cassidy: knowing about real estate, knowing about the various uh uh uhm, social work jobs, and psychiatry jobs, and the lawyer jobs, I started learning this in school from professors.

Cassidy emphasizes the function of knowledge transfers through generations that he's observed to be an advantage of the white bodies which surrounded him. He observed that they were often born into access and handed the tools required to navigate wealth successfully. Cassidy also includes ideas of transferring knowledge in his own personal experience, although his parents did not have all the pieces of the blueprint readily available to pass down. It is important to note that this gap alone was a part of Cassidy's experience in identifying how the transferring of knowledge supported him to where he is today; but also, lack thereof was an integral component that restricted the fluidity of wealth within his own life and of his family line. Meschde et al., (2016) discuss "the stickiness of financial advantage and disadvantage and how those advantages are transmitted from one generation to the next" (p.79); including, the 
generational implications of disadvantages which Cassidy was able to illustrate as they directly impacted his own personal experiences.

Aside from the monetary value that knowledge transfers hold, there are also the physical transfers of monies, property and ownership that contribute to the concept of Black wealth mobility. This element aligns with more conventional understandings of family capital, as Meschde et al., (2016) attributed the differences between a family's ability to build wealth is largely dependent on how inheritance is able to impact the absolute wealth growth and relative wealth mobility (p.88). Participants expressed valuing similar transfers of inheritance through their own experiences, and recognized this as playing a significant role in the experiences of those who surrounded them. As participants spoke about what inheritance looked like for them, they were also asked if there was anything that made their experience unique in comparison to those who surrounded them:

Cassidy:... you know a time share, this is all we can give you. Right, we got a lil' time share for you where you can stay in a cott- you can stay in a holiday inn or you can stay in this time share in Florida that's all we got.-Pause - I don't have no other assets and I got this lil house that you got to give to your younger brother cause you're on your own. Right, that's what we got. Versus many of my other colleagues, they're going to Florida, they're going to the cottage — even the cottage! Black people don't think — 'oh white people go to cottage' - do you realize that's real estate? That's investment, but see, we don't, we're in survival mode all the time. So that's, that's my spiel about all of that. As Cassidy shares his experience, he begins by first crediting the efforts his parents made in being able to transfer tangible assets from which he could financially benefit. He acknowledges that although this transfer may not be what solidifies the mobility of himself and his family, the 
benefits it holds could potentially aid him in doing so. There are a few things I noted as the researcher when listening to Cassidy share his experiences. First, I noted his hesitation when stating: "you can stay in a cott- you can stay in a holiday inn or you can stay in this time share in Florida that's all we got". Secondly, he proceeds to compare this experience to what he would see amongst his colleagues who demonstrated much larger forms of asset transfers; such as property and cottages. I recall noting this hesitation during the focus group, and wondering how it may connect to the comparison he makes of his colleagues. I contend that his tone shift from a sense of exasperated gratitude when discussing the efforts of his parents, to being shocked and almost applaud the degree and value of asset transfers amongst his other peers, highlights a major discrepancy within the Black experience of wealth mobility. This discrepancy is verbally represented as Cassidy identifies his asset transfer and switches from 'cott-(cottages?)' to 'holiday inn' or 'time-share,' where myself as the researcher, and you as the reader can experience a significant shift in motion. This shift demonstrates the numerical findings of Meschde's et al., (2016) study where "white families received substantially more in financial transfers over the study period, totaling on average $\$ 31,938$, versus $\$ 3708$ for black families" (p.81). Through combining Cassidy's real lived experiences, and the findings of Meschde's et al.'s, (2016) study there are consistent patterns that may not necessarily represent every Black Canadian; but call attention to a societal oppression that directly infiltrates Black wealth mobility. Hence, a combination of both physical assets and knowledge transfers through generations represent the first set of integral elements that define Black wealth mobility. Precarious Hustle

The second component of Black wealth mobility was found to be employment capital/consistent income, otherwise described as 'precarious hustle.' Much research discussing 
employment capital revolves around the three characteristics Meschde's et al. (2016) mentioned (benefits, flexible schedule and consistent work) that provide "access to [a] set of wealthbuilding benefits [which] could increase their family assets" (p.83). Although participants did express employment and consistent income being an integral element of building their wealth, less importance was placed on employment benefits and having a position with a flexible schedule. The lack of emphasis on these two elements does not dismiss the important role they play in individuals being able to build wealth; but rather, this lack of emphasis suggests that positions holding strong levels of employment capital are not readily accessible to Black bodies.

Thus, when participants (all Black bodies) engage in the discussion of employment capital being a tool of wealth mobility, it is through drawing from their own experiences that they have navigated with the employment opportunities to which they had access. Moreover, one's ability to maintain a consistent income was a significant indicator of Black wealth mobility. Reese mentions an intriguing concept that he refers to as 'precarious hustle' when he shares his story of navigating wealth mobility:

Reese:... And through my precarious work this year, this being my first year out of school, I was actually able to clear six figures. Through precarious - pause — hustle, so to speak

Researcher \& Cassidy: mhmmmm

Cassidy: yeah

Reese: So I had enough capital then, to leverage that for a mortgage Reese's experience introduces a unique approach to understanding wealth mobility. Initially, only a certain structure of employment was understood as being a useful wealthbuilding tool. Reese challenges this notion by broadening the idea of employment capital to 
include navigating the employment sector and white collar workforce in accessing his own Black wealth mobility. His understanding of employment capital more so came from being able to maintain a consistent income even through precarious work, and then using this income to purchase wealth-building assets.

Cassidy also shares a similar experience as he discusses what his father had done to navigate his own wealth mobility while simultaneously accessing the education system. Cassidy's father lacked access to family transfers forcing him into a similar experience of Reese's concept precarious hustle: "he said mom, dad, I want to go to school, they said that's good. Good luck. And he's like wow, okay, so he had to work CNE jobs."

Cassidy identifies two primary elements that contribute to Black bodies utilizing precarious hustle in developing their wealth mobility. First, he identifies his father's lack of access to family capital transfers being a driving force that led him to precariously hustle in securing seasonal CNE (Canadian National Exhibition) employment so he could finance his education. This illustrates concepts of wealth mobility being highly reliant on the wealth supports of one's caregivers/family members; and if not accessible — fiscal employment then becomes one of the few accessible and viable routes available. Meschde et al., (2016) also makes reference to this 'web of wealth' when explaining "families with access to a well-resourced web of wealth [often] receive help in paying for educational costs, including private school, college..." (p.83). And when considering the realities of those who have lack thereof, the experiences of Francesca Boucher - an African American woman — within Meschde's et al., (2016) study are similar to that of Cassidy's father: 
Describing how she manages financially, she says: “...it’s definitely a trying time. You know, school tuition still has to be paid...You just add in the expense of preparing for college. It's really costly...”. (p.88)

The similarities of these two experiences, although geographically separated and unlikely to have crossed paths, call attention to a second phenomenon within the Black experience that contribute to utilizing precarious hustle in developing wealth mobility. Seeking to further one's education to build human capital carries a financial burden that results in fiercely engaging with precarious employment so individuals are able to match their income with increasing expenses and/or debt. But also, it is important to consider in negating to develop one's human capital by refusing to go to post-secondary education, the possible implications that this carries for future wealth mobility and sustainability are then jeopardized as well.

\section{Show Me What You Know}

As previously discussed the act of capital transfers aids in defining the concept of Black wealth mobility. Specifically, transferring knowledge plays an integral role in the experience of achieving Black wealth mobility and remained a prominent theme within participants' stories. As humans spend their entire existence in a constant state of learning, the process of transferring knowledge was a valuable feature amongst the various forms of capital transfers. And as the researcher I say this because the tool of transferring knowledge was often used when physical or monetary transfers were not readily accessible. Throughout the focus group there was more discussion about what the participants had learned through their life time - either through their personal navigation or through knowledge that had been passed down to them - versus the physical assets they had been able to acquire. Although inheritance may have played a role in 
their navigation today, their emphasis was revolved around being able to learn, build and grow from and within one's own community:

Reese: ...cause really, we don't do shit alone. When it comes to your thesis, when it comes to fucking learning how to ride your bike or wipe your ass, we don't do anything alone, we're drawing on someone else...

Here, I would argue that Reese really calls on the interdependency of Black community, and the process of constantly learning and evolving through supporting one another. Arguably, playing a dual role of resistance in building wealth mobility and also healing the traumas accumulated throughout Black communities. There are two primary pillars that fuel and aid the transfer of knowledge: themes of whiteness, and the power of representation. Within these two pillars, participants also touch on some of the barriers that hinder transfers and thus, one's ability to apply knowledge.

\section{$\underline{\text { Whiteness }}$}

Within the discussion of knowledge transfers, there is an overarching theme of whiteness that arises - especially when participants were discussing acquiring knowledge from sources outside of the Black community and its members. With all the participants being first generation Canadians with immigrant parents (not intentionally selected by the researcher) participants themselves consistently identified an avenue of access, especially for their parents, was from a white (rich) body. Much of the comments made, had me as the researcher questioning the role of white bodies within the experience of acquiring Black wealth mobility:

Cassidy: Because they went to talk to some rich white business man, who said 'hey yeah, this is how you get rich' but they're learning this in their forties! 
When considering the experiences of immigrant bodies who migrate to Canada, and their access to capital transfers - especially knowledge transfers, much of this would be heavily reliant on bodies who have already been able to establish wealth mobility. Bodies who were visibly and socially understood as always being a step ahead of everyone else:

Cassidy:... But that's the problem, much of the knowledge that we're gaining now, about financial stability, talking to some of my white colleagues, they knew about this from grade two, grade three.

Because of this, many participants associated knowledge transfers that were not intentionally passed through their own community, with how white bodies navigate the resources they had access to - information that was unknown otherwise. There were even moments that I noted as the researcher, where participants expressed excitement as they came into new knowledge from white bodies that they had no access to prior. There were elements within participants' tone and expression that hinted at the fact that this knowledge is not readily accessible to 'outsiders' or those continuously pushed to the margins of society:

Reese: ... one of the biggest learnings that I would pass down to anyone is when you're thinking of credit, when you're thinking of finances, capital, leverage, investments, mortgages, real estate, this all comes from building relationships with financial institutions who play with the billions of dollars. That will say here is thirty-thousand dollars we're risking it, if you fail we can take it back but if you're smart enough you can actually take the thirty-thousand, buy a mortgage, have an assignment on that mortgage saying that before it's actually developed you can sell it because the market will increase the value of fifty-thousand before you actually build a house. And then you have fiftythousand in cash before the house is ever built and you buy another house, just bigger, 
and you take that money again and sell it before the house is built again. And that's the game they're playing in this white boy club. - pause - phew!

As Reese explains this process, the exasperation in his tone unveils that this was knowledge he had to work and fight to uncover; and that these are valuable blueprints that white bodies rely on to build their own wealth. This dependency on white bodies to fill gaps of knowledge highlights the importance of intentional and culturally situated knowledge transfers between generations. Reese touches on this briefly as he mentions that is some of the knowledge he would, and plans to intentionally pass down to others and future generations. Although receiving knowledge transfers from white bodies provided aid in working towards Black wealth mobility, participants also acknowledged that techniques of navigation still needed to be discovered as their access differed from that of the white bodies they observed. In contrast, knowledge transfers that were intentionally passed through generations held not only the resources of building wealth mobility, but also how to navigate one's self as a Black body in gaining access--knowledge of Black wealth mobility:

Cassidy: ...Because we were good with our money, because we knew, look we can't waste this opportunity because our parents, like they worked three, four jobs just to get us to this point...

Not only does this identify whiteness as playing a significant role in accessing initial forms of knowledge for both participants and their parents; greater emphasis on the learning process was also attributed to the intentional generational transfers of Black wealth mobility. This point also touches on themes of precarious hustle previously discussed.

\section{$\underline{\text { Power of representation }}$}

Representation, or lack thereof, provides a significant form of indirect knowledge 
transfers. Although social operations centered on white supremacy posit that it is an intentional form of knowledge transferring, its route of reproducing knowledge throughout generations operates as a latent tool. Representation functions to influence our subconscious and substantiate ones understanding of the world around them, including their social positioning as a white or racialized body without it ever having to be overtly or explicitly stated. The lack of representation that participants were exposed to throughout their lifetime had a profound effect on them developing their personal capacities as Black bodies within Canadian society. They discuss not being exposed to people in professional settings or in positions of power who looked like them, and how this functioned to shape their reality and the choices they then made for themselves. Although no stories were shared of participants experiencing overt comments regarding their capabilities as Black bodies, the picture painted was how they came to understand the world around them. And so, throughout the focus group numerous comments were made which alluded to their previous understandings of themselves and the role representation played in creating this perception. Comments such as:

Cassidy: So, when I went, and I got to (university name omitted), and I'm now seeing Black folk but in a more, one could say, a more bourgeousie situation - cause I'm not, I'm not used to that. I'm not used to seeing Black people with money. In my family, in my environment, in my immediate surroundings - so when I'm now here I'm at (university) right, And you know, with, with the name and all and everything I'm like oh my gosh I'm seeing Black folk, I'm like this is crazy. And then they're saying yeah I'm from Brampton, I'm from Mississauga, I'm like oh shoot you got money, money right...

Similarly, Reese commented: 
Reese: but really, until I made it to my Masters I don't think I would have seen myself in a doctoral degree if I didn't meet Julian. You see what I'm saying? That literally opened up like a different path, the first Black professor I ever had. The first Black male teacher I ever had I was like 25.

Having the privilege to see bodies like yourself in positions of power, levels of education or holding certain accomplishments contributes to one's understanding of self and positioning within society. By Reese and Cassidy being exposed to Black bodies holding different experiences outside of what they considered the norm, this shifted not only the way they view themselves but also how they viewed their community. Being able to broaden their view, impacted their individual capacities where they saw themselves exist in spaces painted and ruled by whiteness. Participants described this exposure as a pivotal point that changed the trajectory of their future, really emphasizing the impact knowledge carried through representation and this being passed down through generations. This aids in our understanding of how society shapes the box that Black communities are confined by, in producing generational poverty and a constant state that participants described as being 'in survival mode.' Where lack of access, generational poverty and cyclical trauma situate Black bodies in survival mode; and also, how seemingly effortless this concept fits together with the intergenerational trauma that slavery has imposed onto Black communities.

Community, collective consciousness

As knowledge transfers serve one element of capital transfers, participants also challenged the direction by which the transferring of knowledge should occur. Within their own experiences, they discussed the ways in which they observed intergenerational trauma negatively impacting their parent's/guardian's navigation of Black wealth mobility. Remi makes a comment 
that really resonated with me as the researcher, as she explains the impacts of poverty on Black communities:

Remi: being first gen Canadian I find that a lot of us, uhm, like, -pause - our parents are coming from backgrounds where they didn't have as much. So, at this point in time they, they're more, their focus is more or less, like giving us the lifestyle they did not have. And the opportunities they did not have, and as a result a lot of us become more materialistic. As opposed to trying to save and, you know, obtaining generational wealth. And so, at the point, like, now it's more about breaking that cycle, and teaching other young people about that...

As a researcher I hear this, and I think about the varying impacts trauma has when experienced by an entire community. Up until this point in the discussion, participants focused on the ways in which they received support from their elders, and now we are also being exposed to some of barriers that still remained within this experience. Reese really ties this idea together where these experiences of being in survival mode, especially when prolonged, will have adverse effects on an individual's ability to access financial literacy skills and also it can reinforce behaviours of overcompensation over strategic financial management.

Reese: I-I think really the root of it is we do acknowledge that already we're behind, we're late. And that's not only us, our parents are still kind of uhm, suffering from those intergenerational traumas.

These behaviours of overcompensation are often tied to efforts in protecting future generations from feeling inferior or never having enough, obscuring one's focus into achieving immediate materialistic goals rather than those targeted towards supporting future generations. I would also bring this discussion further into looking at how this behaviour of overcompensation 
is reinforced by the impacts of lack of representation contributes and generational poverty. When considering how these two operating cycles of whiteness have infiltrated Black communities, we can identify the seeds of hopelessness that have been planted within mindsets of Black bodies for us to then play a role in continuing the cycle of our own oppression.

The discussion of intergenerational traumas led participants to calling for a community collective consciousness to be raised. This community collective consciousness challenges the direction initially posed of knowledge transfers. Participants now suggest knowledge transfers as being an ongoing input/output process between and within generations for it to provide healing, resistance and a support for future generations.

Reese: what we really need is, a deep sense of critical consciousness to understand the flow of equity and money, and how these things build back in - because without that consciousness any behaviour we do will be flawed. Like if we don't really understand where the money is going with the purpose, whether it be from the parents to the children, to the children to their behaviours and outcomes, we're gonna fuck it up regardless. So really, we have to take a step back and say 'mom, do you know what this money could do for me if I do this?' and if Mom needs that mentorship we need to be able to get that from grandma, if not grandma then a professor that is a Black person, an elder in the community, someone that has this knowledge to kind of guide us - cause really, we don't do shit alone.

Cassidy: Yup, no, no that makes sense, you're making a good point

Reese's tone alone during this portion of the discussion amplifies the importance of developing a community collective conciseness, and Cassidy reaffirms this statement by agreeing it is necessary for Black communities to build this capacity. Cassidy later comments: 
Cassidy: I think what happens too often is Black people, they need to get these tools, they need to be in this program and do this and do that - which I don't disagree, but we're still asking a hurt people. We haven't dealt with the hurt; so, are you saying we gotta take years and years to deal with the hurt? Well yes, especially, if we're talking the most hurt of our community, right? 'Cause there's different aspects we're not all homogenous. The projects, followed by then the working-class peoples - and we cannot forget our middle and upper class peoples because they may have the money but they're still hurt. We need to deal with the hurt, so we need to have health implementation programs...

This suggestion also identifies major issues within social programming and policy which provide minimal support for collective community building, and fuel funding for programs that target and isolate community issues to the individuals experiencing them. In essence, current social supports provide band-aid solutions that address short term issues on the individual level, rather than developing plans for long-term solutions in repairing the roots of the community.

\section{Ownership}

Within Black wealth mobility, ownership continues to hold a significant role in building the capacity for wealth to be transferred through generations. Various forms of ownership pose the potential for "inheritance or financial transfers [that] have consistently been linked to higher wealth growth and upward wealth mobility" (Meschde et al., 2016, p.88). The value of ownership was consistently discussed amongst participants where a space was created to really dissect the role ownership plays in Black wealth mobility. Two primary perspectives emerged from this discussion, where on one hand land ownership, business ownership and asset ownership all played a large role in the idea of building Black wealth mobility and providing a safety net for bodies who had access — but, only if navigated correctly: 
Cassidy: And then to add to that, the other problem is, it would even be a bit better if our families owned businesses cause then you know what many other cultures do? I f'ed up in school, gonna go work for the family business. Imma work for the pizza joint, Imma go work for the Italian uh uh, pasta joint, I'mma go work for the Chinese grocery store. Imma go work for my uncle, Imma work with my brother.

The safety net that ownership provides ensures members within a family unit are financially secure, regardless of their personal circumstance. But it was very interesting that although participants were very knowledgeable in understanding the potential of ownership within Black wealth mobility, much of its validation came from observing how other communities navigate their wealth mobility.

Cassidy: and the reason I say that is because, you'll go to Markham right - the Chinese own Markham. That's theirs, that's lil China right there right. You go into any bank in Markham, you may see one white person, you may see one Indian person, just to cover the diversity quota. But the Chinese managers, the Chinese owners, the Chinese workers right, so when you're investing the money they're taking out money - how do you think pacific mall is always getting renovated every other minute? How do you think all these others uh uh uh, plazas, and uh projects and grocery stores are getting funding? Right because they have the banks! ... using the bank to leverage, to get that money to build equity is important, but what we also need to do in the Black community in terms of wealth is take that money and invest it back in the community Reese: yeah, yeah, yeah Researcher: uhhhummm 
Cassidy: Right, to the point where when we get enough accountants, enough uh financial experts, enough marketing specialists, we say hey, we need to create our own bank or we need to start applying to these banks and we start to infiltrate.

\section{Cassidy: Yup}

Based on the consensus, arguably, participants pulled from the observed modes of resistance other cultures used to build their wealth mobility within Canadian society. As the discussion continued to unfold, much of the gaps of financial literacy within Black communities prevented the ability for ownership to be acquired; and the ability to navigate it in building generational Black wealth mobility was significantly hindered. Much of this dialogue then drew us back to our prior discussion on the importance of allowing knowledge transfers to happen in a cyclical motion.

Remi: Another thing too I would say to, uhm with building wealth is a lot of Black people, the Black people who do have houses they're not thinking about their children Cassidy: No

Remi: and helping them, them with their houses, like they're thinking about leaving those things behind for them. But they're not thinking of how to help them get houses at this point in time. Right

Cassidy: Yup

Remi: and like, I think going to a lot of uhm, like group, uhm, conferences and learning about uhm, helping your block, like I find that a lot of Black people aren't taking the equity out of their homes to help their children own homes.

Cassidy: Yup. Very true

Reese: Yes 
Remi: I think that something we need to start doing, because the market - pause - it's terrible. pause. Like our parents, like, they need to stop waiting until they're gone to like, give us these things, when they could help you build it from now so that you're building the equity yourself. And you can easily give them back that money once you own a home, because once you build your own equity you have that money there.

There is really something to be said about the varying perspectives and approaches that the younger generation advocates for based on what they observe from the older generation and their behaviours. Although these two groups of bodies belong to the same community, there seems to be a shift in their perspectives of wealth mobility. The older generation seems to have mastered saving and prioritizing (modes of wealth acquisition), while the younger generation may benefit from this, they have also developed an understanding of wealth transference. Participants argue that the strategies initially used for building Black wealth mobility differ once shifting gears from acquisition to the transfer of wealth. Some of the stories shared surrounding experiences of ownership were very focused on the mistakes made which led to loss of ownership, or ownership having an adverse effect on growing and transferring one's wealth:

Cassidy: So - and then my moms, was supposed to have property from my Grandfather he went and sold it in Jamaica! Right, he went and sold and gave it to her siblings, they squandered it, so now she has no property, she has nothing. Right, My, my father he as nothing,

And as participants continued to share their experiences, Cassidy also shared:

Cassidy: Perfect example, my aunt right, she had a winery right. Perfect family business situation, like oh my goodness this is beautiful a winery. She could have passed it down to one of my cousins, she passes it down to her sister and I'm sorry, I love my aunt right, 
but she is an alcoholic and she gets high every other day. You give it to your older sister, knowing her situation, with mental health knowing that's not in check. A year and she already done, we're up to almost twenty grand in debt, the shop is shut down. Value business is (clapping noises) kaput. And I'm like are you kidding me? And this is what happens. So, we don't have that option where it's like you know what, can I just work for the family business. We may have the odd mechanic shop, or pass as a contractor or uncle — we may have that but then

Remi: If you're lucky

Cassidy: If you're lucky, but more times the only family business you got, is selling drugs. So, you know what, I know my cousin sells this rock, or I know my cousin is a pimp so let me go get, put me on some game. And that's the problem, so when people think ugh, these black kids chose to sell drugs - we really don't, right. We really don't, if we did have to sell drugs, we probably wouldn't

Listening to these stories, a few elements stood out that really capture the overarching message. When thinking about wealth mobility, much research is often centered around acquisition of assets, ownership and wealth. When situating the Black body carrying a historical linage of the post-Atlantic slave trade living within modern Canadian society, acquiring knowledge notably takes more precedence. Otherwise, it results in Black bodies acquiring wealth without being able to grow or have long lasting implications for future generations. This connects back to Reese's previous comment about needing communal healing and understanding in order to really build Black wealth mobility. The amount of loss — despite the gains - within Cassidy's experience emphasizes the need to go beyond strategizes of wealth acquisition, to 
strategies of acquiring wealth with the intent of developing a support network for one's family and community.

Cassidy also returns to concepts of survival mode with his last comment, where he mentions the experience of Black bodies being forced to navigate financial stability with limited access to resources and supports while also being faced with numerous barriers. Within my personal experiences, these are the same dynamics I would observe of Black bodies within my immediate communities. Where unconventional means of survival are utilized to ensure the financial security of one's safety, food and shelter. Although the approaches of achieving these goals may differ, in reality, the behaviours and the intent are identical whether one has access to conventional means of achieving them or is forced into making a means for themselves:

Cassidy: ...people think that people in school are different from the drug dealers, what are you talking about? Many of our peers get into the fields that they do with the same mentality I need to make money

Reese: Yup talk di talk dem, tomatoe, tomatoe boy

Cassidy: That's what I'm saying! I need to make money as an engineer, I need to make money as a drug dealer, it's no different. The only difference is one decided imma go the linear path the other decided imma go the street path right

The acknowledgement of realities that are consistently in survival mode challenge the dominant narratives of Black bodies. Dominant narratives which often define them as the undeserving and that individualize community issues. These dominant narratives substantiate the barriers that are posed against developing community supports and also make their funding the most susceptible during government cuts. 
Participants talk about their unique experience being first generation Canadians and the type of barriers unique to this experience which hinder the process of developing ownership. They introduce the idea of the 'barrel kid:' where they are expected to care for families back home due to the global representation of the American Dream. This paints over their lived experiences and realities while also upholding them to crippling responsibilities and expectations.

Remi: And-and I find that a lot of times too, like, with the Black community, as Caribbean people, like our families are still taking care of their families back home Reese: come on, we're, we're barrel kids Cassidy: (exasperated sigh) Yup

Remi: Yup, sending barrels every so often, sending down money — that takes a big hit you know what I mean...like the Caribbean is still so undeveloped so even myself working, like I'm sending money back home to take care of family as well right. And it's a constant, like I feel like it's something that we're all, we'll always be doing.

Cassidy: Yup

Meschde et al., (2016) speak to this generally when explaining that "black household wealth growth is often constrained not only by lower rates of receiving financial assistance, but also by higher rates of providing assistance—financial and non-financial—-to relatives in need" (p.87). But, these participants really add a layer to the experience of these barriers when also accounting for their cultural positioning. Personally, I can attest to similar experiences as well, that not only have a financial impact but can also result in family ties being strained or broken should you fail to comply with supporting those back home. Although I cannot confirm or deny that this is a shared experience amongst immigrant families across Canada, I can confirm that 
this phenomenon is prevalent within the Canadian-Caribbean culture — while being able to confidently state that white Canadians with generations on this land do not share this experience or barriers. Arguably, it is white Canadians upholding and benefiting from this ideology of the American Dream. Whiteness plays a big role in developing an ideology of Canada being abundant in opportunity, gain and equality while simultaneously only upholding this 'abundance' to the restricted few who meet the standards of whiteness and privilege. This does not operate in isolation, but, in sync with all the other barriers posed against Black bodies that hinder their access to stable jobs, access to ownership, access to representation, and access to knowledge. These components play a role in defining Black wealth mobility and the individual navigation towards it.

\section{They Don't Care About You}

Because every participant within this study has an educational background in the social service sector and professional experience working within social services, all participants were able to contribute some of the underlying issues within the structure of social services concerning Black communities. In essence, participants concluded that the regulating bodies within government who create policies and programs for institutions, essentially do not care for the bodies they serve; and arguably, structure service user's programs and policies to benefit those in power. Cassidy identifies the social service sector as being dominated by white supremacist institutions:

Cassidy: ... So the White supremacist system, what is it? The correctional system, child welfare, education, uhm hospital — so they're killing our youth in you know uh in enormous matters. 
When considering the proportion of service users who come into contact with these regulatory, surveilling bodies - regardless of the fact that Black bodies account for a small portion of Canadian society - Black bodies dominate representation within these institutions. So, when Cassidy says 'they're killing our youth' — within this context, this statement is specifically speaking to Black youth. Cassidy discusses his experience as a social service worker attempting to navigate the sector in supporting the youth with whom he has worked; some of the issues he observed regarding the operation of these services were inherently the reasons why there are massive gaps that fail to address the issues of our service users, specifically our Black population. Cassidy challenges the facade that the social service sector attempts to portray as it continues to self-proclaim as the 'saviour' when in reality:

Cassidy: ...you're saying you're providing care — you're providing death. They enter your systems where they end up judicial or homeless, the enter homeless they're dead. Right, so I almost prefer then, let's not even touch the families with our white loving care if we're just going to do the same shit or make it even worse! Instead what we're actually going to do is we're going to take you away and then we're going to benefit because Bob and Brian are going to own the group home and make money off your head — which looks very similar to slavery.

This comment was especially emotional for me as I do not carry as much in-field experience as my participants did; and having their insight really puts into question: is social work salvageable? When considering social service's history rooted in oppression and considering its structure today, the forms of oppression have only changed shape while still maintaining the violence they impose onto Black communities. To the extent, where the internal 
'harm' that may be identified by workers, is still to a lesser extent of the violent possibilities that occur should the social service sector intervene.

As the researcher, I would attribute this level of harm resulting from the fact that some of the social services provided are through privatized structures and operate just like a business, where the amount of revenue (how many bodies access such services) takes precedence over the quality of support and resources they have access to. Essentially, I would argue that when money is involved social services do not care about the outcomes unless they support a revenue model that allows those in power to remain in power. Through this, we can observe how capitalism has infiltrated the very structures deemed responsible for mitigating today's social inequality.

\section{They Don't Care About Us Either}

It is also important to consider the internal struggles of Black bodies within social service positions, as they are expected to carry out 'aid' and 'support' through a capitalist structure where the main objective is generating revenue; and revenue equates to bodies consistently being in need, with low success rates. The complexity of this experience intensifies not only when you realize that the majority of your clients are Black bodies from your own community, but when you also realize that the sectors providing a decent income are those that perpetuate the most harm, and have the deepest roots imbedded in whiteness and oppression:

Cassidy: ... The hospital is a very comfortable position, TDSB work is a very comfortable position. So, when we think social services, we're saying oh yeah there's no money — and there isn't money, unless you're talking the 3 biggest institutions right. Children, health, education — that's where the money is, and anything in-joint with that they don't care about that. 
And so, Black bodies employed through the social service sector are placed in positions where they must compromise their navigation of Black wealth mobility or subscribe to institutions of whiteness which continue to perpetuate harm onto their own community. This same employment position also offers the financial security, shelter and healthcare they have been working towards their entire lives. Some of the ways participants discussed negotiating this pain were through acts of resistance to disrupt the operation of whiteness within social institutions:

Cassidy: Yeah, so that's the sticky situation that I even find myself in that although I know, personally myself that I am making a difference, and being very outspoken in the organization and doing what I have to do, I know at the same time, I have to understand that there are going to be times where, yes, I am going to get pulled in certain situations, or pulled in different directions that I don't want to be in.

With that being said, this also shapes the environment of employment at the frontline when outside of these primary institutions. Although grassroots organizations working at the frontline are those most connected to the community, and arguably providing better resources, care and mindful intent to their service users; they are also the ones that are most underfunded, unsupported and face the largest barriers in gaining access to necessary resources. These are where Black bodies who choose to not participate in these systems of whiteness within the social sector end up being:

Cassidy: when we think of Black people in social work we think grassroots, frontline, burnt out, right, they work with the children's aid workers...that is actually the real work, cause let's be honest - the front line is the real work, ain't no money there. Because they're like well we know who is going to predominantly making up that population. 
Employment within the social service sector creates this conflict where workers have to choose between their own personal Black wealth mobility by working for oppressive institutions, or potentially rejecting their wealth mobility in efforts to support those at the frontline through precarious means. Personally, as I approach graduation and begin looking for employment within the social sector I am conflicted between these two options and the route I will choose in continuing my navigation through Black wealth mobility. I would argue that no path is necessarily the 'right' path, but rather we need Black bodies coming from all sides with their own approach to resistance to really dissolve the violent whiteness that continues to infiltrate our communities, our ethics, and our spaces of work. Within that, I can confidently say that I, and those around me continue this work in our unique ways of gradually resisting and dismantling these oppressive structures. 


\section{CHAPTER 5: MOVING FORWARD--IMPLICATIONS \& CONCLUSION}

This study relied on narrative methodology using focus group methods and thematic analysis to understand the Black wealth mobility experiences of Black service providers and their clients. The previous chapter reported findings of the focus group and alluded to the role of social work. Before expounding on this further, it is important to remind the reader that the findings are limited. For future knowledge to be developed expanding these findings, I would suggest including participants who were from various cultural backgrounds within the Black community to also provide their input, as all the participants identified having a Caribbean background and being first generation Canadians.

Moreover, it is important to acknowledge that the initial purpose of this research was to conclude with potential policies and programs that need to be implemented in order to foster Black wealth mobility. Even the focus group questions were structured to brainstorm ideas and concepts from bodies who were both involved professionally in the social service sector, and had the identity to speak on the experiences of Black communities. Participants expressed a greater need to share their experiences as a Black body navigating wealth mobility while also operating within the social sector and ensuring that these stories were told. Hence, as the researcher, I removed my initial intent of this research and refocused to understanding the pinnacle pieces of the stories shared, including the messages participants intended to engage in and contribute to their knowledge creation. Even as I continued to follow my interview guide and ask:

Researcher: So, like we're all in kind of the social service field, so we're all pretty familiar with either the policies that you inform or the policies you gotta work with when working with clients. Just like a brainstorming session - what are some of policies or programs even that you think would really target some of the issues you guys are talking 
about? Uhm with regard to the parents, with regards to the youth in survival mode, with regard to housing — like what are, like specifically to target Black communities - what are policies and programs you think either are working right now, or that you think need to happen or the changes that need to happen in the existing ones?

The responses that participants provided were actually so far removed from what I had intended the discussion to conclude with, that I was unable to develop a set of policies and programs to answer this question, even with the information gathered thus far. As such, if I were to develop my own set of responses with the stories collected, not only would I be reducing the complexities of participants' experience to be solved by one single policy or program, but I would be completely hijacking their overarching message:

Cassidy: One thing that we do have to do is stop relying on the government to help us. Because the government were the people that oppressed us. And no other group has ever relied on the oppressor to liberate them. They've told them what you're doing is wrong, but no other group has said we need this from you.... so, Black people we need to say okay we aren't doing well for ourselves and we start with little things. So ,you say you know what, I'm going to stop buying from H\&M and I'm going to start investing in some of my colleagues who are selling Black clothing. You know what I'm going to a financial advisor who's Black - the money goes into his pocket. Thats what I started. This is what we need to do, and so when we think we need this magnificent solution. Pass the torch, pass the baton. But Black people we so busy begging and pleading to the government and then we wonder why they can take it away after...it was never yours to begin with... It was never ours to begin with what did you expect? So, if we're talking programs, we need to have community efforts. 
And so, this really concludes the research on a strong note, where participants actually argued that the reliance on the social service sector is actually a problem within itself. Whereas efforts by and within the community itself are where discussions of healing, and knowledge transfers can occur to better support future generations. The only element of Cassidy's narrative that I would argue as the researcher is problematic, are comments that compared Black communities to other racialized communities when asking the government for assistance. Canada holds itself as the caregiver for the people of the land, and enforces policies and programs to protect its population. In many ways, this is the same justification that Canada uses when disproportionately surveilling, punishing and incarcerating Black bodies; and us (as the researcher, participants and reader) dismissing the requests of Black bodies to uphold this responsibility, negates holding Canada accountable for its violence. This is especially important when considering Black communities throughout history that have worked towards this community development, self-reliance and efficiency as previously discussed - Nova Scotia's Africville - in stabilizing their own Black wealth mobility. Yet, such communities were still infiltrated by surrounding white communities and purposely stripped of their resources in efforts to weaken and relocate Black populations across Canada and North America. In conclusion, participants agreed that community efforts need to be centered around the following:

Remi: implementing things like teaching them how to become financially literate. Like in order to receive their funding for OW, they should at least have to attend a course...

Reese: I think that too Remi, just to add to that point — that needs to be something that's done to the broader OW system. Just because I almost want to reproduce a narrative that Black people are on OW - because you look at the numbers, white people actually use it more than us. For me, it comes down to - its so fucking complex that you almost can't 
just give one suggestion. Things are binary and they come from different areas. You gotta look at family, you gotta look at the systems, you gotta look at the workers. But for me there has to be a policy or some institutional culture that acknowledges the idea of antiblack racism and its many manifestations...

Cassidy: My piece is the health component. You know what I see at least with CAS - is we'll refer families to parenting programs, we're refer youth to uhm, we'll get funding for them to get tutoring and we'll say hey parents here's a cheque we'll pay for tutoring. The kids never see tutoring but the parents see that cheque. Right and, you know too often, and you know we give them these tools which is like cool but then we're asking a hurt people... We need to deal with the hurt, so we need to have health implementation programs...

Participants argue if there were programs to be developed they would need to be structured around financial literacy, resistance of anti-black racism, and addressing health systems. With that being said, these programs and policies also need to have the capacity to meet the slew of complex needs within Black populations in order to be effective. This really calls for the need for community efforts to be included if any program or policy were to be developed that directly concerns or addresses Black populations within the GTA in order to ensure the effectiveness of these initiatives.

In ending, the implications for social work in defining Black wealth mobility allow for narratives of counter-story telling to reshape our understanding of the Black racialized experience. In reshaping our understandings as social service providers, we can then develop comprehensive supports for service users within social institutions in providing effective, dynamic and accessible resources. Drawing conclusions from this research, it is understood that 
wealth mobility is an interdependent construct with several operating pieces. Supports developed to address these social gaps then need to be constructed with attributes that are intersecting and multidisciplinary. Otherwise, we see the policies and services developed today which serve as a band-aid solution that does not carry the capacity to address root issues of social inequalities. These solutions simply serve to decrease or increase statistical medians in painting Canada in a positive multicultural light, rather than seeking out and addressing the experiences of the bodies reported within them. Graham et al., (2015) discuss this being a current issue as "job programmes in Canada [streamline] policy direction [that] only supports participation in the precarious labour market through increasing rates of temporary employment opportunities" (p.782). In attempts to address unemployment rates within Canadian communities — increasing opportunities of precarious work becomes the 'solution,' where unemployment statistics improve but the quality of life, stability and access remain remotely the same for Black bodies. This is a scheme Canada relies on to maintain its reputation without addressing societal structures that perpetuate inequalities. Canada has a long history of using policies and programs to paint a picture over experiences of inequalities for the purpose of self-preservation in upholding its worldly image of the multicultural melting pot, free of discrimination, inequality and injustice.

In sum, through participant's stories there emerged several tools that they felt passionate about sharing to navigate the phenomena which shape experiences of Black wealth mobility. The three primary tools of navigating Black wealth mobility include: (1) knowledge transfers, easily comparable to family capital; (2) ownership, tools which build neighbourhood/environment capital; and, (3) navigation of the education system - developing and creating one's human and social capitals. Renaming these capitals not only provides room for them to intersect throughout the discussion, but more accurately encompass the realities of the participants. These same tools 
are what will aid the social service sector in identifying the root of societal oppressions, and strategies for programs and services that resist them. 


\section{APPENDICES}

\section{Appendix A: Recruitment Email Text}

To whom it may concern,

My name is Tasha Riley, and I am currently enrolled in the Masters of Social Work program at Ryerson University. I am currently in the beginning stages of completing my major research paper as apart of my graduate studies program on enabling wealth mobility within Black communities in the Greater Toronto Area. This research study will be supervised by Samantha Wehbi. I am specifically interested in creating social work informed policy and program recommendations to fuel and support economic growth within Black communities. With your educational and professional background I am hoping you would be willing to contribute to this study, or pass it along to anyone who may wish to participate in this study.

I am currently seeking 3 volunteers to take part in my research study. The requirements include the following: (1) Black individuals who identify as being from African descent (2) located in the GTA and (3) a working professional in the field of to social work for at least one year. Participation in this research study is strictly voluntary and there will be no penalties should you decline this offer or choose to withdraw from the study. Participation in this study will entail your contributions to the focus group discussion, expected to last from 1-2 hours. The duration of the focus group will be audio recorded and the facilitator (myself) will be note taking. The audio recording will be a password protected file through transfers from recording device to computer storage. The recording will be destroyed upon submission of final research report in August 2019. Transcripts and participant email contacts will be password protected and also destroyed in September 2019. All data collected will be used for transcription and thematic analysis - which will be provided for participants review to ensure the accuracy of data and its results. 
Due to the format of this study, the limitations of confidentiality are contained by other participants and myself. The stated security precautions will be taken place to prevent personal identification from being possible, and also the maintenance of participant confidentiality will be encouraged during the focus group amongst participants.

Potential risks include social repercussions if participant data is not kept confidential and emotional vulnerability in discussing difficult experiences. To manage these risks, every effort will be made to ensure that participant confidentiality is maintained through data storage procedures. Participants will also have the ability to decline or withdraw from the study at any point, and refuse to engage in any moments of the discussion.

The focus group will take place the month of March. Exact date and location will be set based on participants' availability and accessibility.

I appreciate your taking the time to read this and pass it on if you so choose. This study has been approved by Ryerson's Research Ethics Board.

If you are interested in the study or obtaining more information about the study please feel free to contact me at the email provided below within 5 business days of this email being sent. Thank you in advance for your time and consideration.

Sincerely, Tasha Riley, BSW

School of Social Work at Ryerson University 


\section{Appendix B: Consent Form}

You are being invited to participate in a research study. Please read this consent form so that you understand what your participation will involve. Before you consent to participate, please ask any questions to be sure you understand what your participation will involve.

\section{BLACK WEALTH MOBILITY: LESSONS FOR SOCIAL WORK}

\section{INVESTIGATORS:}

This research study is being conducted by Tasha Riley, supervised by Dr. Samantha Wehbi, from the School of Social Work at Ryerson University.

If you have any questions or concerns about the research, please feel free to contact tasha.riley@ryerson.ca or Samantha Wehbi at swehbi@ryerson.ca

\section{PURPOSE OF THE STUDY:}

The purpose of this study is to explore the experiences of Black bodies working towards attaining or maintaining their financial stability to generate wealth mobility, within and throughout generations. For this study, wealth mobility is defined as the individual ability to accumulate, grow and increase assets to ensure one's financial stability; including that of their family. This concept can also extend generational wealth and ability to transfer accumulated wealth and assets within a lifetime.

Participants who contribute to this research will do so voluntarily. The criteria of participation will include all of the following: (1) working professionals in the field of Social Work for at least 1 year (2) Located and working done in the GTA (3) Black participants who identify as having African descent. This study will include three participants. This study is also being completed by a graduate student as a requirement for completion of their degree.

\section{WHAT YOU WILL BE ASKED TO DO:}

If you volunteer to participate in this study, you will be asked to do the following things:

Participate in a focus group session, you will be asked to share your experiences of maintaining and attaining wealth mobility and financial stability. 
Specifically, the researcher will be looking for themes in experiences that result from racism and create barriers. Also examined are experiences highlighting personal acts and work done with clients as forms of resistance to these barriers.

The expected duration of interview is two hours, the expected meeting location is Ryerson University or a library of participants' choosing; whichever is more convenient for the participant, and as long as this location gurantees aural and visual privacy.

Participants can expect interview questions such as the following:

2. I would like to hear about your story and experiences around gaining financial stability; what that meant for you, what were some of the milestones and barriers, as well as where you see yourself today in terms of gaining wealth mobility. You can tell this story in whatever way you feel best represents you and you are free to leave out anything you don't wish to share.

Have you ever viewed aspects of your identity (race) impacting this journey/process? Can you identify events that presented barriers tied specifically to your identity?

What experiences do you define as acts of resistance to gain access to opportunities of wealth mobility?

3. I would like to hear about your story and experiences when working with Black clients and your working experiences in attaining or maintaining wealth mobility in gaining financial stability; the milestones and barriers throughout the process.

Were there moments where you acted in resistance to aid your clients in getting the financial supports they required?

Were there specific policies and/or programs that aided in this process or made it more difficult?

Did you find your clients' experiences were impacted by their racialized identity?

4. I would like to discuss how a combination of your personal experiences and your work with clients has guided how you navigate yourself and others to opportunities of wealth mobility.

-What resources did you rely on or forms of resistance used to gain access? What aspects of this resource/resistance benefitted you better than mainstream/traditional options?

-What policies hinder or provide access to forms of wealth mobility? 


\section{POTENTIAL BENEFITS:}

The potential benefits of this research include an opportunity for participants to share and bond over their personal experiences belonging to the same communities. This sharing of experiences will also contribute to furthering growing literature which resists dominant narratives of Black communities and targets solutions to persisting concerns. From this study, findings will contribute to discussions of identifying structural issues and also developing solutions to address persisting concerns. As the researcher, I cannot guarantee nor state that the focus or goal of this research will result in any personal benefits for participants.

\section{WHAT ARE THE POTENTIAL RISKS TO YOU AS A PARTICIPANT}

Participation in this study is low risk. The potential risks throughout the duration of this study may include discomfort when asked questions, as the nature of research questions requires personal reflections on personal experiences of structural oppressions and racialization; including the experiences based on work done with clients. For some, sharing these experiences may be difficult and may result in feeling upset or uncomfortable. No participants will be required to answer questions they do not feel comfortable answering, and will not be punished for doing so. Participants are reminded they can take breaks, skip questions or stop participation, either temporarily or permanently. Names will not be used as identifying factors in the final report of this research study. Protection of your identity is discussed below.

\section{CONFIDENTIALITY AND DATA STORAGE:}

There will be extensive measures on part of the researcher to ensure a participant's identity remains anonymous. Pseudonyms (fake names) will be assigned to you. Other potential identifying information, for example names of schools, will be censored. Personal information including date of birth and address will not be recorded nor included in the report.

Information provided by you will only be viewed by the researcher and if necessary transcript excerpts with no identifying information will be shared with the research supervisor. Information will not be accessible to any other parties.

The interview will be audio recorded. You will have the ability to review the transcript and omit information from it. The audio recording will be a password protected file through transfers from recording device to computer storage. The recording will be destroyed upon submission of final research report in August 2019. Transcripts and participant email list will be password protected 
and also destroyed in September 2019. Signed consent will be secured and stored for one year after the research study has been completed, at which point it will be shredded.

\section{INCENTIVES FOR PARTICIPATION:}

No incentives will be provided for your participation.

\section{COSTS TO PARTICIPATION:}

No reimbursement will be provided for your participation.

\section{VOLUNTARY PARTICIPATION AND WITHDRAWAL:}

Your participation in this study is completely voluntary throughout its entire duration. You can choose whether to be in this study or not; state if any question makes you uncomfortable; or if you would like skip a question. You may stop participating at any time without facing any penalties for your withdrawal. If you choose to stop participating, you may also choose to not have your data included in the study. Please make me aware of this choice by May 1, 2019. Your choice of whether or not to participate will not influence your future relations with Ryerson University or the investigator Tasha Riley involved in the research.

\section{QUESTIONS ABOUT THE STUDY:}

If you have any questions about the research now, please ask. If you have questions later about the research, you may contact:

\section{Tasha Riley}

Researcher, MSW Candidate tasha.riley@ryerson.ca Samantha Wehbi Supervisor swehbi@ryerson.ca

This study has been reviewed by the Ryerson University Research Ethics Board. If you have questions regarding your rights as a participant in this study please contact:

Research Ethics Board

c/o Office of the Vice President, Research and Innovation Ryerson University 350 Victoria Street

Toronto, ON M5B 2K3 
416-979-5042

rebchair@ryerson.ca

\section{BLACK WEALTH MOBILITY: LESSONS FOR SOCIAL WORK}

\section{CONFIRMATION OF AGREEMENT:}

Your signature below indicates that you have read the information in this agreement and have had a chance to ask any questions you have about the study.

You have also been told that by signing this consent agreement you are not giving up any of your legal rights.

Name of Participant (please print)

Signature of Participant Date

I agree to uphold the confidentiality of other participants in the focus group.

Signature of Participant Date

I agree to be audio-recorded for the purposes of this study. I understand how these recordings will be stored and destroyed.

Signature of Participant Date 


\section{Appendix C: Interview Guide}

\section{Introduction}

Thank you for agreeing to participate in this study. As a reminder, today's focus group will be centred around your personal experiences attaining wealth mobility, and the experiences you encounter when working with Black clients in their aims of attaining/maintaining financial stability. Through your storytelling I will be taking notes to identify strategies of resistance you have utilized through personal experience and also to benefit your clients. I will also take note of barriers you identify, and hopefully draw on potential policy and program design/focus which would align with your acts of resistance. I want to make sure that you remember that we can stop the interview or I can stop recording at any point during the interview. This interview will not be very formal, and it will be up to you to determine how long you will need to tell your story. I do have a few questions for you but you are free to answer as few or as many of them as you are comfortable with. Ultimately, it is your story I want to hear and you may decline to answer anything at any time. Further, I would like to mention that since the nature of the topic being discussed is quite personal, there is not an expectation that you have an answer to every question, or that you are willing to provide details of every experience.

\section{Background}

Before I ask you to tell me about your story I would like to start by defining wealth mobility, and perhaps recreating it to fit personal understandings of wealth mobility.

I have defined wealth mobility as being the individual ability to accumulate, grow and increase assets to ensure one's financial stability, including that of their family. This concept can also extend generational wealth and ability to transfer accumulated wealth and assets within a lifetime.

a) Is there anything more to include, or anything you would like to exclude

\section{Story}

I would like to hear about your story and experiences around gaining financial stability; what that meant for you, what were some of the milestones and barriers, as well as where you see 
yourself today in terms of gaining wealth mobility. You can tell this story in whatever way you feel best represents you and you are free to leave out anything you don't wish to share.

\section{Possible Guiding Questions:}

- Have you ever viewed aspects of your identity (race) impacting this journey/process?

- $\quad$ Can you identify events that presented barriers tied specifically to your identity?

- What experiences do you define as acts of resistance to gain access to opportunities of wealth mobility?

\section{Client Experiences}

I would like to hear about your story and experiences when working with Black clients and your working experiences in attaining or maintaining wealth mobility around gaining financial stability; the milestones and barriers throughout the process.

- Were there moments where you acted in resistance to aid your clients in getting the financial supports they required?

- Were there specific policies and/or programs that aided in this process or made it more difficult?

- Did you find your clients experiences were impacted by their racial identity?

\section{Social-work Informed Policy \& Program suggestions}

I would like to discuss how a combination of your personal experiences and your work with clients has guided how you navigate yourself and others to opportunities of wealth mobility.

- What resources (programs, community resources, individual relations) or strategies (techniques/tactics) did you utilize to access wealth mobility and economic stability? What elements did you find enabling of this tactic and/or resource?

- What policies hinder or provide access to forms of wealth mobility?

\section{Concluding remarks}

I would like to thank you for taking the time to sit and speak with me about your experiences. Are there any comments, questions or concerns you would like to address before concluding this focus group? 
I will be sure to share the findings of the interview with you once I have finished the study and have left my contact information with you for this reason. Further, I would welcome your input and/or critique upon completion of the study. Thank you again for your time and for sharing your knowledge with me. 


\section{Appendix D: Ethics Clearance Certificate}

\section{$\begin{array}{ll}\text { Research } \\ \text { Ryerson } & \text { Ethics Board }\end{array}$ University}

To: Tasha Riley

Social Work

Re: REB 2018-473: Black Wealth Mobility: Lessons for Social Work

Date: January 25, 2019

Dear Tasha Riley,

The review of your protocol REB File REB 2018-473 is now complete. The project has been approved for a one year period. Please note that before proceeding with your project, compliance with other required University approvals/certifications, institutional requirements, or governmental authorizations may be required.

This approval may be extended after one year upon request. Please be advised that if the project is not renewed, approval will expire and no more research involving humans may take place. If this is a funded project, access to research funds may also be affected.

Please note that REB approval policies require that you adhere strictly to the protocol as last reviewed by the REB and that any modifications must be approved by the Board before they can be implemented. Adverse or unexpected events must be reported to the REB as soon a possible with an indication from the Principal Investigator as to how, in the view of the Principal Investigator, these events affect the continuation of the protocol.

Finally, if research subjects are in the care of a health facility, at a school, or other institution or community organization, it is the responsibility of the Principal Investigator to ensure that the ethical guidelines and approvals of those facilities or institutions are obtained and filed with the REB prior to the initiation of any research.

Please quote your REB file number (REB 2018-473) on future correspondence.

Congratulations and best of luck in conducting your research.

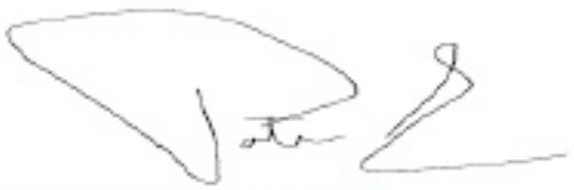

Dr. Patrizia Albanese, $\mathrm{PhD}$

Chair, Ryerson University Research Ethics Board 


\section{REFERENCES}

ANTI-BLACK RACISM. (2018). Retrieved February 27, 2019, from

http://blackhealthalliance.ca/home/antiblack-racism/

Bell, L.A.. (2009). Storytelling, Self, Society: An Interdisciplinary Journal of Storytelling

Studies: (pp. 107-118).

Block, Sheila and Grace-Edward Galabuzi (March 2011). Canada's Colour Coded Labour Market. Ottawa: Canadian Centre for Policy Alternatives and the Wellesley Insitute.

Retrived from http://www.wellesleyinstitute.com/wpcontent/uploads/2011/03/Colour Coded Labour_MarketFINAL.pdf

Bowman, S. W. (2016). Who and what you know: Social and human capital in black middleclass economic decision-making. Race and Social Problems, 8(1), 93-102. Retrieved from doi:http://dx.doi.org.ezproxy.lib.ryerson.ca/10.1007/s12552-016-9169-6।

Branker, R. R. (2017). Labour market discrimination: The lived experiences of english-speaking caribbean immigrants in toronto. Journal of International Migration and Integration, 18(1), 203-222. Retrieved from doi:http://dx.doi.org.ezproxy.lib.ryerson.ca/10.1007/s12134-016-0469-x

Charles, C. Z., Kramer, R. A., Torres, K. C., \& Brunn-bevel, R. (2015). Intragroup heterogeneity and blackness: Effects of racial classification, immigrant origins, social class, and social context on the racial identity of elite college students. Race and Social Problems. Retrieved from. doi:http://dx.doi.org.ezproxy.lib.ryerson.ca/10.1007/s12552-015-9157-2

Clairmont, D. (2009). Razing africville: A geography of racism. Canadian Journal of Sociology (Online), 34(3), 920-922. Retrieved from 
http://ezproxy.lib.ryerson.ca/login?url=https://

search-proquest-

com.ezproxy.lib.ryerson.ca/docview/196352949?accountid=13631

Clarke, V., \& Braun, V. (2014). Using Thematic Analysis In Psychology. Encyclopedia of

Critical Psychology, 77-101. doi:10.1007/978-1-4614-5583-7_311

Connelly, M. F., \& Clandinin, J. D. (1990). Stories of experience and narrative inquiry

Educational Researcher, 19(5), 2-14. doi:10.2307/1176100

Connell, R. (2007). Chapter Ten. Social science on a world scale. In Southern Theory.

CONTENTA, S. (2018). Toronto is segregated by race and income. And the

numbers are ugly. The Star. Retrieved from https://www.thestar.com/

news/

gta/2018/09/30/toronto-is-segregated-by-race-and-income-and-the-

numbers-are-

ugly.html

GRAHAM, J. R., SHIER, M. L., \& EISENSTAT, M. (2015). Young adult social networks and labour market attachment: Interpersonal dynamics that shape perspectives on job attainment. Journal of Social Policy, 44(4), 769-786.

Hasford, J. (2016). Dominant cultural narratives, racism, and resistance in the workplace: A study of the experiences of young black canadians. American Journal of

Community Psychology, 57(1), 158-170.

doi:http://dx.doi.org.ezproxy.lib.ryerson.ca/10.1002/ajcp. 12024

Herring, C., \& Henderson, L. (2016). Wealth inequality in black and white: Cultural and structural sources of the racial wealth gap. Race and Social Problems, 8(1), 4-17. doi:http://dx.doi.org.ezproxy.lib.ryerson.ca/10.1007/s12552-016-

9159-8 
Kolivoski, K. M., Weaver, A., \& Constance-Huggins, M. (2014). Critical race theory: Opportunities for application in social work practice and policy. Families in Society: The Journal of Contemporary Social Services, 95(4), 269-276.

https:// doi-org.ezproxy.lib.ryerson.ca/10.1606/1044-3894.2014.95.36

Meschede, T., Thomas, H., Mann, A., Stagg, A., \& Shapiro, T. (2016). Wealth mobility of families raising children in the twenty-first century. Race and Social

Problems, 8(1) 77-92.

Messer, C. M. (2011). The Tulsa race riot of 1921: Toward an integrative theory of collective violence. Journal of Social History, 44(4), 1217-1232.

Social Development Canada. (2013). Snapshot of racialized Poverty in Canada.

Retrieved February 20, 2019, from https://www.canada.ca/en/employment-socialdevelopment/programs/communities/reports/poverty-profile-snapshot.html

Solorzano, D. G., \& Yosso, T. J. (2002). Critical race methodology: Counter-storytelling as an analytical framework for education research. Qualitative Inquiry, 8(1), 23-44.

doi: $10.1177 / 107780040200800103$

Subotnik, Daniel (1998) "What's Wrong with Critical Race Theory: Reopening the Case for Middle Class Values," Cornell Journal of Law and Public Policy 7(1). Retrieved from http://scholarship.law.cornell.edu/cjlpp/vol7/iss3/1

Tecle, S. (2016, Winter). ANTI-BLACKNESS. Canadian Dimension, 50, 22-24,5. 